\title{
Accessing Performance of Transport Sector Considering Risks of Climate Change and Traffic Accidents: Joint Bounded-Adjusted Measure and Luenberger Decomposition
}

Xiaodong Chen ( $\nabla$ chenxiaodongtzxy@gmail.com )

Sichuan Agricultural University https://orcid.org/0000-0002-5839-7886

Jiahao Zhu

Sichuan Agricultural University - Chengdu Campus

Fang Wang

Sichuan Agricultural University - Chengdu Campus

\section{Research Article}

Keywords: Climate change risk, Traffic accident risk, Technological progress, Decomposition analysis, Bounded adjusted Measure, Transport sector

Posted Date: May 10th, 2021

DOI: https://doi.org/10.21203/rs.3.rs-460622/v1

License: (c) (1) This work is licensed under a Creative Commons Attribution 4.0 International License. Read Full License

Version of Record: A version of this preprint was published at Natural Hazards on September 29th, 2021. See the published version at https://doi.org/10.1007/s11069-021-05046-4. 
1 Accessing Performance of Transport Sector Considering Risks of Climate

2 Change and Traffic Accidents: Joint Bounded-Adjusted Measure and

3 Luenberger Decomposition

4

5 Xiaodong Chen ${ }^{\mathrm{a} *}$, Jiahao Zhu ${ }^{\mathrm{a}}$, Fang Wang ${ }^{\mathrm{a} *}$

$6{ }^{a}$ College of Management, Sichuan Agricultural University, Chengdu, 611130, PR 7 China

8

* Corresponding author: chenxiaodongtzxy@gmail.com (Chen. X) wangfangscnd@sicau.edu.cn (Wang, F)

\section{Word Count: 7926.}

\section{Abstract}

Green transformation of energy use in China's transport sector will promote sustainable development in the country. This paper extends the Bounded-adjusted Measure and Luenberger indicators to detect the performance of China's inland transport sector across 2006-2015. In the framework, the climate change and traffic accident risks are taken as undesirable outputs. In addition, source-specific and variable-specific decomposition are proposed for investigating the sources of inefficiency and productivity, and quantifying the contributions of climate change and traffic accident risks. This paper opens up the "black box" of technological progress, identifying the different channels (i.e., quantity and time dimensions) through which affect economic growth. Therefore, policymakers can find out the most effective pathway to boost productivity growth and mitigate climate change and traffic accident risks in transport sector, which are ignored in the conventional framework.

Empirical results indicate great variances exist among 30 provinces in inefficiency scores, productivity change and technological progress. Hence, classified 
regulations help to tackle this issue. We cluster 30 provinces into 4 groups according to their technological progress along quantity and time dimensions. Variable-wise, $\mathrm{CO}_{2}$ emission-reduction and civil vehicles gains promote the TFP gains most. Also, we verify that economic development and environmental regulations can coordinate to promote the sustainable development of transport sector.

Keywords: Climate change risk; Traffic accident risk; Technological progress; Decomposition analysis; Bounded adjusted Measure; Transport sector

\section{Introduction}

Transport sector, plays an important role in promoting sustainable development worldwide (Legacy, 2015; Li et al., 2019; Monios, 2019). Economic growth brings rapid progress of industrialization and urbanization, which will mainly in turn result in traffic pressures (e.g., traffic congestion, traffic accidents and greenhouse gas emissions) (Liu, Triantis and Sarangi, 2010; Hao et al., 2015; Zhao and Hu, 2019; Huang et al., 2019). Hence, properly addressing the aforementioned posers requires us to figure out the impacts of traffic congestion, traffic accidents and GHG emissions on transport sector. On one hand, World Health Organized (WHO) (2018) issued Analysis report on global road traffic safety situation claimed that annual fatalities due to traffic accidents reached 1.35 million worldwide. On the other hand, climate change has been a global poser facing humankind (Pilli-Sihvola et al., 2010; Jin, Wang and Gao, 2015; Bohr, 2020). As the most important contributor of greenhouse gases $(\mathrm{GHG})$, carbon dioxide $\left(\mathrm{CO}_{2}\right)$ is the main factor resulting in global warming, accounting for nearly $90 \%$ of the global average temperature rise (Huang et al., 2019). Indeed, transport sector, as the major $\mathrm{CO}_{2}$ emitter, contributed to about $23 \%$ to the overall $\mathrm{CO}_{2}$ emissions globally (IEA, 2014). In face of aforementioned undesirable outputs, policy regulations on transport sector are promulgated internationally. 
Properly addressing the aforementioned problems needs international efforts, including the developing countries. Notably, China, as the largest developing country, is regarded as the engine for economic growth. Also, the rapid development brings by-products. Encountering these issues, authorities in China has been dedicated to formulating regulations on transport sector. Recently, the Development Planning of Modern Comprehensive Transportation System issued by the State Council in China in the 13th Five-Year Plan pointed out that by 2020, the country will achieve following goals: (1) In general, the country will build an overall safe, convenient, efficient and green modern comprehensive highway transport sector. (2) Some particular regions and areas must take the lead in basically realizing the modernization of transportation. The plan further detailed that the overall investment in highway transportation sector will reach 15 trillion $\mathrm{CNY}$, among which railway will reach 3.5 trillion, highway will reach 7.8 trillion, civil aviation will reach 0.65 trillion, and water transportation will reach 0.5 trillion (National Development and Reform Commission, 2017).

The rapid development of Chinese transport sector brings byproducts e.g., traffic accidents, traffic congestion and $\mathrm{CO}_{2}$ emissions. Indeed, the overall death result from traffic accidents reached 63194 in 2018 (National Bureau of Statistics, 2019). Looking at traffic congestion, the direct economic loss caused by traffic congestion is equivalent to $5 \%$ - $8 \%$ of GDP every year, up to 250 billion CNY (Ministry of Transport of the People's Republic of China, 2019). Turning to $\mathrm{CO}_{2}$ emissions in transport sector, the $\mathrm{CO}_{2}$ emissions of transportation industry are 781 million tons, accounting for $8.7 \%$ of the total $\mathrm{CO}_{2}$ emissions of fuel consumption (IEA, 2016).

The Total Factor Productivity (TFP) denotes the share of outputs that can not be explained by the change of inputs. As a comprehensive indicator, TFP accounts for a large percent for economic growth (Ilmakunnas and Miyakoshi, 2013). Hence, many 
studies have been dedicated to seeking for the driving force of TFP growth in firm-level, city-level, nation-level and international level. However, they all focused on the "all-in-one" composite productivity indicator, this fails to reveal the impact mechanism of productivity on economic growth. On this basis, this paper open up the "black box" of productivity, revealing the channels or pathways through which it affects the economic growth.

Previous scholars provided theoretic and empirical guidance in the related field for the current paper (Cooper et al. 2001; Cullinane et al., 2005; Fleisher et al., 2010; Venturini, 2015; Gehringer, 2015; Beier, 2019). Indeed, the operation performance of transportation has been widespread investigated (Tian, et al., 2014; Kannan and Hirschberg, 2016; Pettersson et al., 2018). Importantly, Oum et al., (2013) employed a DEA-based approach, together with alternative approaches for the measurement and comparison of social efficiency across firms in different transport modes. Seufert et al., (2017) developed a DEA-based Luenberger-Hicks-Moorsteen productivity indicator to measure the airline operational performance. Mahmoudi, et al., (2019) introduced a DEA considering game-DEA for the sustainability assessment of urban transportation system. Saeedi et al., (2019) extended a network DEA method to measure the performance of different intermodal freight transport chains inside a freight network. Indeed, data envelopment analysis (DEA) proposed by Charnes et al., (1978) can be a effective approach in measuring relative efficiency among Decision-making Units (DMUs). The approach can be used to measure the environmental efficiency in transport sector and we can obtain the corresponding TFP changes and technological progress with various approaches (e.g., Luenberger productivity indicator (LPI); Mamlquist index; Hicks-Moorsteen index) (Daraio et al, 2016; Liu et al., 2019). Chang and Tovar (2017) performed a Metafrontier analysis on productivity change in west Coast of South Pacific terminals with a DEA-Malmquist approach and further explained the differences in productivity change with a dynamic panel estimation, and revealed that catch-up effect and technological regress prevail. 
Miao et al., (2019a) employed the Slack-based Measure (SBM) and Luenberger Productivity Indicator $(L P I)$ in order to measure the static inefficiency and productivity change in China's 30 provinces, revealing that NOx emissions in transport sector is an important source for inefficiency and productivity gains. Feng and Wang, (2018) introduced a global meta-frontier DEA for measuring energy efficiency measurement in transport sector, revealed that technological progress is the main factor for productivity gains.

Though aforementioned conventional DEA models and approaches contributed to the accuracy of TFP measurement, these methods can not satisfy the multi-objective decision making and suffer certain drawbacks. For example, subjective parameter setting is required for Slack-based Measure, which render the deviation to the real productivity change. As for Range-adjusted Measure (RAM), the range composes the parameter that will destroy the discriminatory power, and induce infeasible solutions assuming constant returns to scale (CRS). The Bounded-adjusted Measure proposed by Cooper et al., (2011), on the basis of additive structure, can well address these drawbacks. Furthermore, the treatment of static inefficiency determines the accuracy of productivity change. Additive-based Luenberger Productivity Indicator and multiplicative-based Mamlquist index have been the most prevailing approaches for measuring productivity change. Indeed, additive-based LPI is a more flexible one that can perform the source-specific decomposition and variable-specific decomposition. Boussemart et al., (2020) did a expended decomposition on Luenberger Productivity Indicator and applied the model to Chinese healthcare sector, found that productivity growth is mainly driven by technological progress.

The current paper mainly provides contributions methodologically and empirically as follows. Firstly, we construct a framework that incorporates multi-inputs and multi-outputs involving passenger and freight systems. Then, the managerial 
disposability is set for transportation-related energy use implicating that clean-energy use and structure adjustment are obtained. Thirdly, a systemic decomposition framework for Luenberger indicators is introduced, i.e., source-specific and variable-specific one (as shown in Fig. 1). Last but not the least, the channels of technological progress on economic growth are revealed from the quantity and time dimensions.

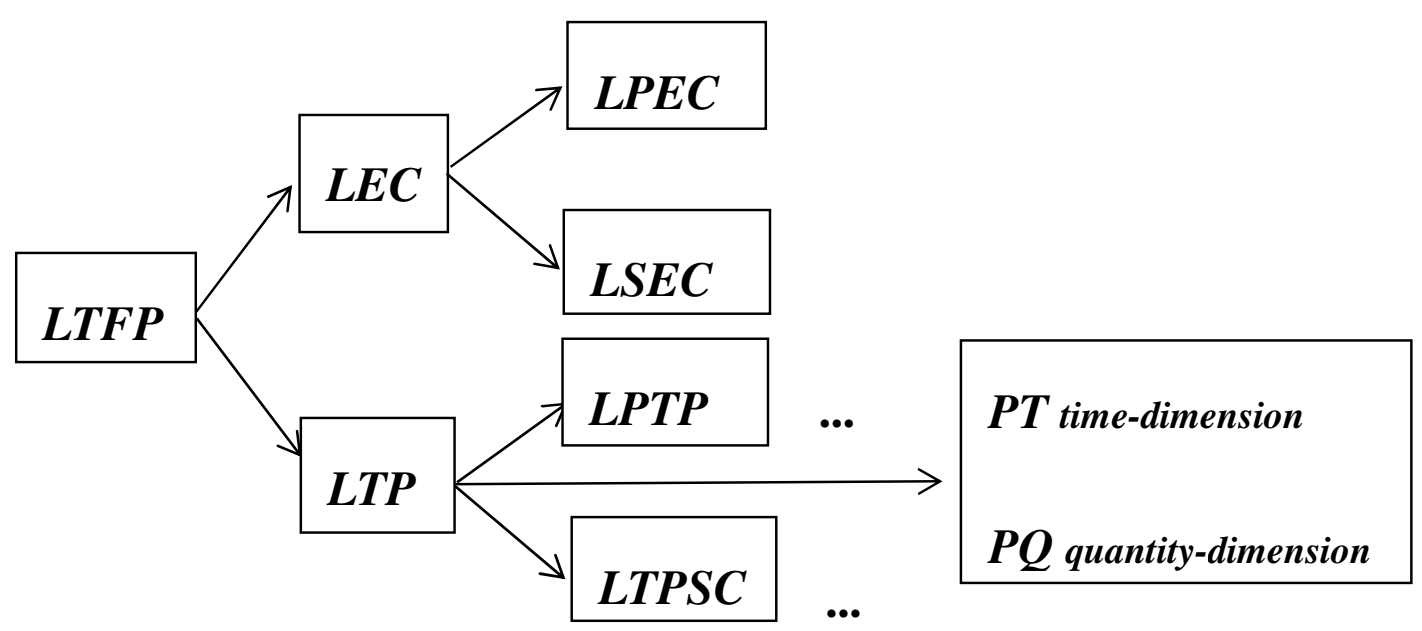

Fig. 1. decomposition process for $L P I$

The following parts are organized in a coherent manner. Section 2 introduces the quantitative methods in computing TFP, along with the approach illustration on novelty. Data source and settings are investigated in Section 3. Sections 4 brings empirical analysis which details the inefficiency and productivity change, as well as the decomposition results. Conclusion remarks and policy recommendations are provided in Section 5.

\section{Quantitative methods}

In order to perform variable-specific and source-specific decomposition analysis of the productivity change of transport sector in China's regional level, we extend the 
approach for productivity change decomposition introduced by Chen et al. (2020). Specifically, we first need to establish the current and global frontier on the basis of the panel data from multiple time spans (i.e., 2006-2015 in the study). Then, province-level panel data in China are used, and a province-level regions is taken as a decision-making unit (DMU). This section shows the detailed calculation process of inefficiency scores through BAM and productivity change relying on the LPI.

\subsection{Static inefficiency measurement}

\subsubsection{Production technology}

Transport sector, as a comprehensive system network, can be regarded as a production process that transforms energy use and conventional input (i.e., non-energy inputs, e.g., labor force, capital stock and vehicle quantities) into desirable outputs (e.g., transport turnover and economic outputs) and undesirable outputs (e.g., traffic casualties and $\mathrm{CO}_{2}$ emissions) (Wang et al., 2011; Fan and Lei, 2016; Hang et al., 2019; Chen, Wu and Li, 2019).

In the current paper, we consider possession of registered civil vehicles, fixed capital stocks, labor force and energy use in transport sector as inputs, transport turnover and output as desirable outputs and traffic casualties and $\mathrm{CO}_{2}$ emissions as undesirable outputs (Stefaniec et al., 2020). Eq. (1) presents the details.

$$
P T^{t}=\left\{\left(E_{1}^{t}, P^{t}, K^{t}, L^{t}, D^{t}, Y^{t}, T_{1}^{t}, E_{2}^{t}, T_{2}^{t}, C\right):\left(E^{t}, P^{t}, K^{t}, L^{t}\right) \operatorname{can} \operatorname{produce}\left(Y^{t}, T_{1}^{t}, T_{2}^{t}, C\right)\right\}
$$

As is shown in Eq. (1), the variable set $\left(E_{1}^{t}, P^{t}, K^{t}, L^{t}\right)$ represents energy use of inland transport $(E)$, possession of registered civil vehicles $(P)$, fixed capital stock in transport sector, storage, and post $(K)$ and employment in transport, urban units, traffic, storage, and post $(L)$ respectively. The variable set $\left(D^{t}, Y^{t}, T_{1}^{t}, E_{2}^{t}, T_{2}^{t}, C\right)$ denotes the value-added of the inland transport sector $(Y)$, transport turnover (T1), traffic death (T2) and $\mathrm{CO}_{2}$ emissions in transport sector $(C)$. Indeed, the variable set $P T^{t}$ is 
defined as a close set, suggesting that the transformation from inputs to outputs is limited and null-jointness and strong disposability can be assumed (Färe and Grosskopf, 2004).

$$
\begin{aligned}
P T^{t}=\left\{\left(E_{1}^{t}, P^{t}, K^{t}, L^{t}, Y^{t}, T_{1}^{t}, T_{2}^{t}, C\right):\right. & \sum_{i=1}^{I} \lambda_{i} e_{a i} \geq e_{a}(a=1, \Lambda, A), \\
& \sum_{i=1}^{I} \lambda_{i} p_{b i} \leq p_{b}(b=1, \Lambda, B), \\
& \sum_{i=1}^{I} \lambda_{i} k_{f i} \leq k_{f}(f=1, \Lambda, F), \\
& \sum_{i=1}^{I} \lambda_{i} l_{g i} \leq l_{g}(g=1, \Lambda, G), \\
& \sum_{i=1}^{I} \lambda_{i} y_{j i} \geq y_{j}(j=1, \Lambda, J), \\
& \sum_{i=1}^{I} \lambda_{i} t_{1 m i} \leq t_{1 m}(m=1, \Lambda, M), \\
& \sum_{i=1}^{I} \lambda_{i} t_{2 n i} \leq t_{2 n}(n=1, \Lambda, N), \\
& \sum_{i=1}^{I} \lambda_{i} c_{p i} \leq c_{p}(p=1, \Lambda, P), \\
& \sum_{i=1}^{I} \lambda_{i}=1
\end{aligned}
$$

In the aforementioned Eq. (2), $\lambda$ represents the positive intensity vector, whereas $i$ denote $i$-th decision-making unit (DMU). Further on, $e, p, k, l, y, e_{2}, t_{1}, t_{2}, c$ is the matrices of quantities of inputs, desirable outputs, and undesirable outputs respectively. With constraint $\sum \lambda=1$, the underlying technology becomes variable returns to scale (VRS) one. When there are no constrains on $\lambda$, constant returns to scale (CRS) is maintained.

\subsubsection{BAM model assuming managerial disposability for energy use}

Bounded-adjusted Measure (BAM) is a non-radial and non-oriented model that can detect subtly differences among decision-making units (DMUs) (Cooper et al., 2011). This indicates the model have strong discriminatory power which can be attributed to 
its parameter ${ }^{1}$. In addition, the model is flexible and suitable for any returns to scale (RTS).

Indeed, the basic model treat all input-oriented variables in the same manner (i.e., natural disposability). The natural disposability implies that producers may reduce generation of the undesirable outputs by adjusting production, i.e. given reduction in the input vector leading to reduced undesirable outputs, maximize the desirable outputs. However, with rapid process of urbanization and industrialization, the energy use has greatly turned into cleaner mode. Therefore, the novel treatment manner for energy use variable is necessary. For addressing the problem, Sueyoshi and Goto (2011, 2012) introduced the managerial disposability, which have certain policy implications. Specifically, assuming managerial disposability, producers maximize production of the desirable outputs while minimizing generation of the undesirable outputs and increasing the use of inputs. With regards to the energy use, this can be explained as using cleaner energy instead of coal, oil and other fossil energy related to pollutant emissions.

The current paper will apply natural disposability to conventional input variables and managerial disposability to energy use. For simplicity, we arrange possession of registered civil vehicles $(P)$, fixed capital stock in transport sector, storage, and post $(K)$, and employment in transport, urban units, traffic, storage, and post $(L)$ into conventional inputs, and separate energy use. In addition, value-added of the transport sector $(Y)$ and transport turnover $(T 1)$ are incorporated into desirable outputs and traffic death (T2) and $\mathrm{CO}_{2}$ emissions in transport sector $(C)$ into undesirable outputs. The introduced model is for calculating the static inefficiencies of the transport sector.

\footnotetext{
${ }^{1}$ The parameter for Range-adjusted Measure is constituted by range which may induce high efficiency scores and make it difficult to distinguish frontier (see Cooper et al. 2011 for more detains). This can be well handled by BAM.
} 
The additive structure BAM can be detailed as :

$$
\begin{aligned}
B A M-I E= & \frac{\sum_{q=1}^{Q} S_{q}^{x} / L_{q}^{x}+\sum_{r=1}^{R} S_{r}^{e} / U_{r}^{e}+\sum_{v=1}^{V} S_{v}^{y} / U_{v}^{y}+\sum_{w=1}^{W} S_{w}^{z} / L_{w}^{z}}{Q+R+V+W} \\
\text { s.t. } \sum_{i=1}^{I} \lambda_{i} x_{q i}+S_{q}^{x}=x_{q i}, \sum_{i=1}^{I} \lambda_{i} e_{r i}-S_{r}^{e}=e_{r i} ; & \\
& \sum_{i=1}^{I} \lambda_{i} y_{v i}-S_{v}^{y}=y_{v i}, \sum_{i=1}^{I} \lambda_{i} z_{w i}+S_{w}^{z}=z_{w i} ; \\
& \sum_{i=1}^{I} \lambda_{i} x_{q i} \geq \min \left(x_{p i}\right), \sum_{i=1}^{I} \lambda_{i} e_{r i} \leq \max \left(e_{r i}\right) ; \\
& \sum_{i=1}^{I} \lambda_{i} y_{v i} \leq \max \left(y_{v i}\right), \sum_{i=1}^{I} \lambda_{i} z_{w i} \geq \min \left(z_{w i}\right) ; \\
& \sum_{i=1}^{I} \lambda_{i} \geq 0, \forall q, r, v, w \geq 0, S_{q}^{x}, S_{r}^{e}, S_{v}^{y}, S_{w}^{z}, \lambda_{i} \geq 0
\end{aligned}
$$

Where variable set $\left(x_{p i}, e_{r i}, y_{v i}, z_{w i}\right)$ denotes the quantities of conventional inputs, energy inputs, desirable outputs and undesirable outputs of the $i$-th DMU in time period $t$ respectively. Variable set $\left(S_{q}^{x}, S_{r}^{e}, S_{v}^{y}, S_{w}^{z}\right)$ represents slack variable set of conventional inputs, energy use, desirable outputs and undesirable outputs respectively. Variable set $\left(L_{q}^{x}, U_{r}^{e}, U_{v}^{y}, L_{w}^{z}\right)$ defines the difference between lower bound (upper bound) and the observed values of conventional inputs, energy use, desirable outputs and undesirable outputs as follows:

$$
\begin{aligned}
& L_{q}^{x}=x_{q i}-\min \left(x_{q i}\right), q \in Q, i \in I, \\
& U_{r}^{e}=\max \left(e_{r i}\right)-e_{r i}, e \in E, i \in I, \\
& U_{v}^{y}=\max \left(y_{v i}\right)-y_{v i}, v \in V, i \in I, \\
& L_{w}^{z}=z_{w i}-\min \left(z_{w i}\right), w \in W, i \in I
\end{aligned}
$$

In addition, it is noteworthy that if $i$-th input satisfies $x_{q i}=\min \left(x_{q i}\right)$, the optimal condition is found (i.e., $S_{q}^{* x}$ ). Then, we define $S_{q}^{* x} / L_{q}^{x}=0$. Likewise, we can define: 


$$
\begin{aligned}
& S_{q}^{* x} / L_{q}^{x}=0, \text { if }\left(x_{q i}\right)=\min \left(x_{q i}\right) ; \\
& S_{r}^{* e} / U_{r}^{e}=0, \text { if } \max \left(e_{r i}\right)=\left(e_{r i}\right) ; \\
& S_{v}^{* y} / U_{v}^{y}=0, \text { if } \max \left(y_{v i}\right)=\left(y_{v i}\right) ; \\
& S_{w}^{* z} / L_{w}^{z}=0, \text { if }\left(z_{w i}\right)=\min \left(z_{w i}\right)
\end{aligned}
$$

239 Further on, the investigation of productivity change force us to perform the 240 variable-specific decomposition. Cooper et al., (1999) introduced the input-oriented 241 and output-oriented decomposition that attribute inefficiency to overall inputs and overall outputs. Cooper et al., (2007) proposed the variable-specific decomposition method for Slack-based Measure (SBM). On this basis, the current paper introduces a decomposition approach that can attribute overall inefficiency to individual variable for BAM.

246 Inefficiency attributed to conventional inputs: $I E_{x}=\frac{\sum_{q=1}^{Q} S_{q}^{x} / L_{q}^{x}}{Q+R+V+W}$

247 Inefficiency attributed to energy use: $I E_{e}=\frac{\sum_{r=1}^{R} S_{r}^{e} / U_{r}^{e}}{Q+R+V+W}$

248 Inefficiency attributed to desirable outputs: $I E_{y}=\frac{\sum_{v=1}^{V} S_{v}^{y} / U_{v}^{y}}{Q+R+V+W}$

249 Inefficiency attributed to undesirable outputs: $I E_{z}=\frac{\sum_{w=1}^{W} S_{w}^{z} / L_{w}^{z}}{Q+R+V+W}$

\subsection{AAT-TFP measurement}

251

In order to continue on the analysis of Average Annual Transport Total Factor 253 Productivity (AAT-TFP) of China's 30 province-level regions, the study considers energy use of transport $(E)$, possession of registered civil vehicles $(P)$, fixed capital 
stock in transport sector, storage, and post $(K)$, and employment in transport, urban units, traffic, storage, and post $(L)$, value-added of the transport sector $(Y)$, transport turnover $(T 1)$, traffic death $(T 2)$ and $\mathrm{CO}_{2}$ emissions in transport sector $(C)$ as variables. Furthermore, component of inefficiency given in Eqs. (6)-(9) can be further broken down in terms of individual variables as shown in Eq. (10)..

$$
I E=I E_{E}+I E_{P}+I E_{K}+I E_{L}+I E_{Y}+I E_{T 1}+I E_{T 2}+I E_{C}
$$

Take all observations associated with different time spans into consideration for constructing a global frontier, technical efficiency can then be captured for each sample time period. In addition, the relevant productivity change can then be calculated by considering the dynamics in the global inefficiencies for the adjacent time periods. Indeed, the mixed disposability for inputs in BAM is employed for computing technical inefficiency (IE). On one hand, technical inefficiency measured against the global frontier is termed the global inefficiency $(G I E)$. On the other hand, technical inefficiency measured against the frontier spanning observations from a sample period is termed contemporaneous inefficiency $(C I E)$. what is more, the technology gap (TG) is comprised of the difference captured between these two measures. Note that subscript index $v$ is employed to represent the variable returns to scale (VRS) estimators, whereas subscript index $c$ denotes the constant returns to scale (CRS) estimators. Furthermore, the comprehensive relationship of the aforementioned two measures associated with the global and contemporaneous frontiers is shown as follows:

$$
G I E_{c}(t)=C I E_{c}(t)+T G_{c}(t)
$$

Drawing from Oh (2010), the Average Annual Total Factor Productivity change of transport sector is calculated as:

$$
\operatorname{AATFP}_{t}^{t+1}=\operatorname{GIE}_{c}(t)-\operatorname{GIE}_{c}(t+1)
$$

Indeed, $A A T F P>0$ indicates productivity gains, whereas $A A T F P<0$ suggests 
productivity decline. In addition, the measures of $T G$ and $C I E$ set off the two terms of the LPI, namely catch-up effect (efficiency change, $A A E C$ ) and frontier movement (technological progress, $A A T P$ ):

$$
\begin{gathered}
A A E C_{t}^{t+1}=C I E_{c}(t)-C I E_{c}(t+1) \\
A A T P_{t}^{t+1}=T G_{c}(t)-T G_{c}(t+1)
\end{gathered}
$$

Assuming VRS estimator permits expanding the source-specific decomposition. On one hand, average annual efficiency change $(A A E C)$ term can be further broken down into pure efficiency change ( $L P E C)$ and scale efficiency change (LSEC). On the other hand, technological progress $(A T T P)$ can be further broken down into average annual pure technological progress $(L P T P)$ and average annual technological progress of scale change (LTPSC). The calculation process are presented below:

$$
\operatorname{LPEC}_{t}^{t+1}=\operatorname{CIE}_{v}(t)-\operatorname{CIE}_{v}(t+1)
$$

$$
\operatorname{LSEC}_{t}^{t+1}=\left[\operatorname{CIE}_{c}(t)-C I E_{c}(t+1)\right]-\left[C I E_{v}(t)-C I E_{v}(t+1)\right]
$$

$$
L P T P_{t}^{t+1}=T G_{v}(t)-T G_{v}(t+1)
$$

$$
\operatorname{LTPSC}_{t}^{+1}=\left[T G_{c}(t)-T G_{c}(t+1)\right]-\left[T G_{v}(t)-T G_{v}(t+1)\right]
$$

As this study focuses on the operation performance of transport sector, we decompose the productivity change in Eq. 12 (and its terms in Eqs. 15-18) in terms of the eight variables presented in Eq. 10. Note that one can identify the productivity change related to energy use or other variables of interest. Since the paper focuses on the transport sector, we then term the presented productivity change as Average Annual Transport Total Factor Productivity $(A A T-T F P)$ in the following parts.

Note that the DEA model shown in this sub-section implies specific assumptions which can possibly influence the inefficiency scores and productivity change obtained. 
Indeed, the underlying technology and the inefficiency measurement can be defined in DEA models. In addition, when constructing the AAT-TFP indicator, the use of the inefficiency measurement also vary greatly in terms of the decomposition approach. In the current paper, natural disposability technology is set for non-energy inputs, whereas managerial disposability is considered for energy inputs. This delivers certain policy implications, where natural disposability decrease inefficiency scores through curbing inputs and managerial disposability decrease inefficiency scores by expanding inputs.

What is more, Miao et al., (2019b) emphasized that the sustainable development of economy depends on technological progress to a great extent. Indeed, the sustainable development of transport sector also remarkably relies on technological progress (Cohen and Jones, 2020). Especially, against the background of fast industrialization and urbanization in China, transport production technologies are dedicated to promoting a comprehensive transport network and gaining output value added, whereas ignoring traffic accidents and greenhouse gas emissions. Hence, exploiting the paths of technological change has been a necessity, whereas ignored by the existing literature. In order to comprehensively model the effects of technological change on $A A T-T F P$, specific problems ought to be addressed in perspective (Miao et al., 2019b). Specifically, (1) from long-term time-dimension, how can we measure the technological progress? (2) from long-term quantity-dimension, how can we quantify the technology gap between worst-performance time period and a certain time period? (3) from technological progress perspective, how can we investigate the relationship between long-term time-dimension and quantity-dimension? The decomposition of Eq. (14) fails to address these questions. The further decomposition of technological change components in transport sector can proclaim the differences of technological change patterns across different regions. Then, the suitable and reasonable technologically innovative transport strategies for promoting comprehensive and sustainable development. 
By exploring the Eq. (14), we can model the average annual technological in the long-term:

$$
A A T P_{t}^{+1}=T G_{c}(t)-T G_{c}(t+1)=\left[T G_{c}(i)-T G_{c}(t+1)\right]-\left[T G_{c}(i)-T G(t)\right]=P T_{i}^{+1}-P T_{i}^{t}
$$

As presented in Eq. (19), $T G_{c}(i)-T G_{c}(t+1)$ denotes technological gap between $i$-th time period and $t+1$-th time period, further referred as $P T_{i}^{t+1}$. Likewise, $T G_{c}(i)-T G_{c}(t)$ refers to the technological gap between $i$-th time period and $t$-th time period, further referred as $P T_{i}^{t}$.

In particular, when we set constrains on parameter $i$, certain implications can be delivered.

Assumption (1): when $i=1$ (in Eq. 20), the technology gap between the initial time period and $t$-th time period and $t+1$-th time period can then be presented respectively.

$$
A A T P_{t}^{+1}=T G_{c}(t)-T G_{c}(t+1)=\left[T G_{c}(1)-T G_{c}(t+1)\right]-\left[T G_{c}(1)-T G(t)\right]=P T_{1}^{+1}-P T_{1}^{t}
$$

Assumption (2): when $i$ is defined as the time period that owns the maximum technological change, then $T G_{c}(i)$ is termed as $T G_{c}^{\max }$ (presented in Eq. 21). In brevity, $P Q_{t+1}^{\max }\left(P Q_{t}^{\max }\right)$ is used to represent $T G_{c}^{\max }-T G_{c}(t+1)\left(T G_{c}^{\max }-T G_{c}(t)\right)$, i.e., the technological gap between certain time period $t+1$ (t) and a specific sample point with worst-technology performance. (i.e., time-dimension and quantity-dimension) decomposition results can be obtained: 


$$
\begin{aligned}
A A T P_{t}^{t+1} & =T G_{c}(t)-T G_{c}(t+1)=\alpha\left\{\left[T G_{c}(1)-T G_{c}(t+1)\right]-\left[T G_{c}(1)-T G(t)\right]\right\} \\
& +(1-\alpha)\left\{\left[T G_{c}^{\max }-T G_{c}(t+1)\right]-\left[T G_{c}^{\max }-T G_{c}(t)\right]\right\} \\
& =\alpha\left(P T_{1}^{t+1}-P T_{1}^{t}\right)+(1-\alpha)\left[P Q_{t+1}^{\max }-P Q_{t}^{\max }\right]
\end{aligned}
$$

In Eq. (22), $\alpha$ is defined as a weight parameter that belongs to [0, 1]. In particular, when $\alpha=1 / 2$, average time- and quantity- dimension decomposition results are then obtained (the particular situation is employed in Miao et al., 2019b). The decomposition process in presented as Fig. 1.

In conclusion, one can attribute the overall inefficiency scores and overall productivity change into individual variable. In addition, the source-decomposition can then be performed for productivity change into efficiency change and technological change. What is more, we can explain the trends of technological change along time- and quantity-dimensions by comparing technological gap (TG) against different assumptions. Noteworthy, similar decomposition process can be applied to average annual pure technological progress $(P T P)$ and average annual technological progress of scale change (TPSC) with interest.

\section{Data sources}

This paper relies on the non-parameter model (BAM) and Luenberger indicators that involve the transformation from inputs to outputs. Note that lack of data in Tibet autonomous region force us consider the remaining 30 province-level regions in mainland China as decision-making units. The time span across 2006-2015 that corresponds to the China's $11^{\text {th }}-12^{\text {th }}$ Five-Year Plan are taken as research sample. Note that part of data is from Stefaniec et al. (2020) Specifically:

(1) Energy use ( $E$, Mtce): $E$ denotes the energy use in transport sector. Indeed, energy use is considered as a important variable in transport sector. Following Chen et al., (2019) and Huang et al., (2019), energy use is considered as a input variable. In 
addition, we assume the converse disposability for energy use and other input variables in transport sector. The primary data set was drawn from the China Energy Statistical Yearbook. Drawing from CESY, (2016), conversion factors to coal equivalent is employed.

(2) Civil vehicle $\left(P, 10^{4}\right.$ units): $P$ represents possession of registered civil vehicles. Wang, (2019) and Stefaniec, et al., (2020) incorporated civil vehicle as their input variable, which has been the theoretical basis for the current paper. Indeed, the data set was derived from the online database of the National Bureau of Statistics of China (NBSC, 2020).

(3) Capital stock $\left(K, 10^{8} \mathrm{CNY}\right): K$ holds fixed capital stocks in transport, storage, and Post. The primary data was drawn from from the online database of the National Bureau of Statistics of China (NBSC, 2020). Indeed, Perpetual Inventory Method (PIM) used in Krautzberger and Wetzel, (2012) and Li, et al., (2016) is followed.

(4) Labor force ( $L$, persons): $L$ is specific with employment in transport, urban units, traffic, storage, and post. Following Chen et al., (2019) and Stefaniec, et al., (2020), the variable is set as an input in the current paper. The data was drawn from the online database of the National Bureau of Statistics of China (NBSC, 2020).

(5) Value-added $\left(Y, 10^{8} \mathrm{CNY}\right): Y$ denotes value-added of the transport sector, storage and post. This study refers to Cui and $\mathrm{Li}$, (2014), takes value added as desirable outputs. The data was drawn from the online database of the National Bureau of Statistics of China (NBSC, 2020).

(6) Turnover $\left(T 1,10^{8}\right.$ ton-km): $T 1$ represents the total passenger and freight turnover of highways, railways, and waterways. We refer to Stefaniec, et al., (2020), and set transport turnover as desirable output. The data was drawn from the online database of the National Bureau of Statistics of China (NBSC, 2020). Note that, according to Chang et al., (2013), passenger turnover was transformed into freight turnover units in the paper. 
407 (7) Traffic casualties ( $T 2$, persons): $T$ holds number of deaths and people injured in 408 traffic accidents. Indeed, according to Chen et al., (2020), traffic accidents are 409 considered as undesirable outputs. However, some minor traffic accidents are hard to 410 identify and thus we consider traffic casualties as a proxy variable. The data was 411 drawn from the online database of the National Bureau of Statistics of China (NBSC, 412 2020).

413 (8) Carbon dioxide emissions $\left(C, \mathrm{Gg} \mathrm{CO}_{2}\right): \mathrm{CO}_{2}$ emissions from the fossil fuel 414 combustion of transport vehicles. Following Mahdiloo et al., (2018), $\mathrm{CO}_{2}$ emissions 415 are treated as undesirable outputs. According to IPCC, (2006), the fuel-based carbon 416 footprint model is used to calculated the emissions, while electricity usage is excluded.

417 The data set was from China Energy Statistical Yearbook.

419 Table 1 presents the descriptive data of these eight variables for 30 province-level 420 regions across 2006-2015.

422 Table 1. Descriptive statistics for the input/output variables in the framework

\begin{tabular}{lrrrrr}
\hline Variable & Year & Maximum & Minimum & Mean & $\begin{array}{r}\text { Standard } \\
\text { deviation }\end{array}$ \\
& & & & & \\
\hline Energy use $(E$, Mtce $)$ & 2006 & 491438.88 & 9209.00 & 157589.12 & 120913.01 \\
& 2015 & 24982.96 & 1485.36 & 9042.61 & 5430.02 \\
& & & & & \\
Civil vehicle $\left(P, 10^{4}\right.$ units $)$ & 2006 & 428.95 & 13.34 & 122.92 & 96.42 \\
& 2015 & 1510.81 & 78.18 & 541.71 & 396.39 \\
& & & & & \\
Capital stock $\left(K, 10^{8} \mathrm{CNY}\right)$ & 2006 & 347800.00 & 21900.00 & 151988.13 & 82119.88 \\
& 2015 & 498233.00 & 29580.00 & 207161.93 & 110026.94
\end{tabular}




$\begin{array}{lrrrrr} & 2006 & 2233.22 & 148.38 & 956.99 & 556.90 \\ \text { Labor force }(L, \text { persons }) & 2015 & 13841.94 & 993.50 & 6514.81 & 3365.62\end{array}$

$\begin{array}{lrrrrr} & 2006 & 1208.82 & 34.92 & 443.66 & 309.36 \\ \text { Value-added }\left(Y, 10^{8} \mathrm{CNY}\right) & & & & & \\ & 2015 & 2928.90 & 90.55 & 1110.82 & 766.66\end{array}$

$\begin{array}{lrrrrr} & 2006 & 13892.41 & 171.73 & 2877.25 & 3260.26 \\ \text { Turnover }\left(T 1,10^{8} \text { ton-km) }\right. & & & & & \\ & 2015 & 19597.78 & 524.53 & 5653.20 & 4879.10\end{array}$

$\begin{array}{lrrrrr} & 2006 & 76465.00 & 1861.00 & 17301.90 & 15585.38 \\ \text { Traffic casualties (T2, persons) } & & & & & \\ & 2015 & 33316.00 & 1323.00 & 8576.63 & 6904.02\end{array}$

\begin{tabular}{ccrrrr} 
Carbon dioxide emissions $(C$, & 2006 & 35369.79 & 612.86 & 11031.99 & 8747.23 \\
$\left.\mathrm{Gg} \mathrm{CO}_{2}\right)$ & 2015 & 51200.31 & 2917.22 & 18075.99 & 11129.93 \\
\hline
\end{tabular}

424 Table 1 presents the statistics data for 2006 and 2015 in mainland China. As shown in 425 the table, in the transport sector, civil vehicle, capital stock and labor force present 426 increasing trend. Conversely, energy use in transport sector decreased, indicating 427 regulations have positive effects in general. As regards output-oriented variables, 428 value-added and turnover volume display rapid increasing trend. On the contrary, 429 traffic casualties show the opposite trend. Noteworthy, effects of $\mathrm{CO}_{2}$ emissions 430 abatement policies is limited. Table 2 shows the changing rates of input/output 431 variables across 2006-2015 in China.

432 Table 2. the rates of change in China's transport sector across 2006-2015, \%

\begin{tabular}{lllllllll}
\hline Province $^{2}$ & $E$ & $P$ & $K$ & $L$ & $Y$ & $T 1$ & $T 2$ & $C$ \\
\hline
\end{tabular}

\footnotetext{
${ }^{2}$ Note that we present abbreviations of provinces in Table 2, and in the following context we will mainly use the abbreviation for sake of brevity.
} 


\begin{tabular}{|c|c|c|c|c|c|c|c|c|}
\hline Beijing (BJ) & -95.26 & 123.24 & 35.35 & 428.41 & 116.14 & 41.80 & -56.06 & 29.55 \\
\hline Tianjin (TJ) & -96.24 & 245.39 & 33.19 & 743.46 & 141.26 & -78.14 & 0.55 & -2.37 \\
\hline Hebei (HEB) & -95.31 & 368.75 & 10.55 & 709.77 & 151.36 & 110.67 & -47.83 & 29.09 \\
\hline Shanxi (SHX) & -91.71 & 285.82 & 21.48 & 714.98 & 102.44 & 96.97 & -52.33 & 151.63 \\
\hline $\begin{array}{l}\text { Inner-Mongolia } \\
\text { (IN-MON) }\end{array}$ & -96.71 & 345.89 & 38.19 & 550.05 & 150.21 & 138.02 & -54.16 & -10.31 \\
\hline Liaoning (LN) & -94.82 & 265.85 & 17.91 & 584.45 & 197.56 & 175.36 & -38.12 & 51.12 \\
\hline Jilin (JL) & -92.86 & 334.24 & 4.36 & 658.25 & 123.71 & 116.15 & -59.85 & 117.36 \\
\hline Heilongjiang (HLJ) & -94.42 & 274.20 & 2.93 & 583.93 & 100.84 & 27.36 & -50.63 & 64.63 \\
\hline Shanghai (SH) & -96.25 & 163.67 & 54.18 & 224.57 & 75.98 & 41.07 & -83.24 & 5.96 \\
\hline Jiangsu (JS) & -92.59 & 415.33 & 44.28 & 437.95 & 183.72 & 128.93 & -46.16 & 110.25 \\
\hline Zhejiang (ZJ) & -94.28 & 351.19 & 54.20 & 340.22 & 156.92 & 123.87 & -58.24 & 63.37 \\
\hline Anhui (AH) & -88.91 & 427.11 & 51.67 & 519.09 & 118.03 & 431.66 & -17.61 & 216.97 \\
\hline Fujian (FJ) & -91.69 & 386.07 & 73.10 & 883.19 & 196.90 & 184.80 & -63.31 & 145.22 \\
\hline Jiangxi (JX) & -92.62 & 483.67 & 42.17 & 276.10 & 117.10 & 217.24 & -62.71 & 107.30 \\
\hline Shandong (SD) & -96.46 & 404.90 & 56.76 & 698.30 & 109.81 & 34.88 & -52.76 & -0.64 \\
\hline Henan (HEN) & -92.08 & 419.15 & 42.88 & 330.10 & 144.75 & 156.04 & -65.98 & 129.41 \\
\hline Hubei (HUB) & -94.65 & 404.99 & 21.70 & 708.13 & 188.03 & 249.16 & -55.65 & 53.66 \\
\hline Hunan (HUN) & -93.51 & 453.49 & 13.86 & 882.60 & 192.78 & 105.88 & -33.15 & 90.64 \\
\hline Guangdong (GD) & -94.80 & 243.02 & 43.25 & 524.13 & 142.29 & 248.23 & -56.43 & 50.64 \\
\hline Guangxi (GX) & -94.62 & 450.08 & 7.70 & 913.81 & 240.70 & 215.32 & -57.44 & 54.22 \\
\hline Hainan (HAN) & -89.79 & 333.13 & 27.56 & 831.09 & 166.84 & 82.79 & 47.97 & 200.62 \\
\hline Chongqing (CQ) & -90.94 & 396.90 & 110.98 & 769.98 & 193.27 & 223.16 & -43.61 & 160.29 \\
\hline Sichuan (SC) & -94.86 & 387.90 & 56.42 & 1156.92 & 167.39 & 125.05 & -61.63 & 41.34 \\
\hline Guizhou (GZ) & -90.74 & 492.81 & 41.30 & 1017.25 & 376.99 & 91.95 & -62.67 & 180.68 \\
\hline Yunnan (YN) & -94.35 & 322.10 & 22.36 & 595.70 & 74.49 & 111.54 & -18.33 & 64.88 \\
\hline Shaanxi (SH'X) & -93.08 & 478.76 & 40.07 & 577.57 & 144.39 & 168.58 & -46.86 & 103.07 \\
\hline Gansu (GS) & -92.30 & 542.40 & 14.16 & 563.15 & 61.96 & 103.50 & -29.46 & 127.36 \\
\hline
\end{tabular}




\begin{tabular}{lcccccccc}
\hline Qinghai (QH) & -83.87 & 486.06 & 30.65 & 746.22 & 159.31 & 205.43 & -7.90 & 376.00 \\
Ningxia (NX) & -94.22 & 498.70 & 35.07 & 569.58 & 256.86 & 184.29 & -42.49 & 61.49 \\
Xinjiang (XJ) & -91.84 & 370.17 & 69.46 & 520.78 & 223.71 & 95.81 & -33.41 & 133.54 \\
Average & -93.19 & 371.83 & 37.26 & 635.32 & 159.19 & 138.58 & -43.65 & 96.90 \\
\hline
\end{tabular}

433

434 For simplicity, Table 2 lists the changing rates of eight core variables in China's

435 transport sector across 2006-2015. Specifically, among 30 provinces, as regards

436 energy use, most provinces have rates of change larger than $-90.00 \%$, apart from

437 HAN, AH and QH (-89.79\%, $-88.91 \%$ and $-83.87 \%$ resp.). This indicates that these

438 province-level regions are lagged in transport energy-conversation as a whole. For

439 civil vehicle possession, GS and NX are possessed with highest rates of change

440 (542.40\% and $498.70 \%$ resp.), whereas SH and BJ have the opposite trend (123.24\%

441 and $163.67 \%$ resp.). Looking at capital stock, CQ and FJ have the best performance

442 (110.98\% and $73.10 \%$ resp.), while JL and HLJ hold the other extreme $(4.36 \%$ and

$4432.93 \%$ ). Turning to labor force, SC and GZ show explosive growth on changing rates

444 (1156.92\% and $1017.25 \%$ resp.), whereas SH and JX have converse trend $(224.57 \%$

445 and $276.10 \%$ resp.). As for value-added, GX and GZ increase greatly $(240.70 \%$ and

$446376.99 \%$ resp.) whereas YN and GS is lagged (74.49\% and 61.96\% resp.). Looking at

447 traffic turnover, only TJ have decreasing trend. For traffic casualties, only TJ show

448 increasing trend. Hence, the performance obtained in rates of change in TJ is terrible.

449 Finally, the decreasing rate of change relative to $\mathrm{CO}_{2}$ emissions is observed in TJ,

$450 \quad$ IN-MON and SD $(-2.37 \%,-10.31 \%$ and $-0.64 \%)$.

452 Generally speaking, the average changing rates associated with energy use and traffic 453 casualties hold obvious decline trend (-93.19\% and $-43.65 \%$ resp.), whereas that of 454 civil vehicles and employment display steep increasing trend (371.84\% and $635.32 \%$ 455 resp.). For $K, L$ and $C$, spatial distribution characteristics of performance is better in 456 southeastern costal areas and go decreasing to northwestern provinces. 


\section{Empirical results}

459

460

461

462

463

464

465

466

\subsection{Transport Inefficiency}

The framework introduced in section 2 will induce inefficiency scores both under CRS and VRS assumptions ${ }^{3}$. We can obtain the inefficiency scores in transport sector for 30 province-level regions. In addition, we term the inefficiency as global inefficiency (i.e., GIE) due to the construction of the global frontier. What is more, the additive structure BAM permits the variable-specific decomposition, as shown in Table 3 .

Table 3. Inefficiency scores of transport sector in 30 China's province-level regions

\begin{tabular}{lccccccccc}
\hline \multicolumn{1}{c}{ Province } & $G I E$ & $E$ & $P$ & $K$ & $L$ & $Y$ & $T 1$ & $T 2$ & $C$ \\
\hline Beijing (BJ) & 0.03 & 0.00 & 0.01 & 0.01 & 0.00 & 0.00 & 0.00 & 0.01 & 0.00 \\
Tianjin (TJ) & 0.07 & 0.00 & 0.01 & 0.02 & 0.02 & 0.00 & 0.01 & 0.02 & 0.00 \\
Heibei (HB) & 0.00 & 0.00 & 0.00 & 0.00 & 0.00 & 0.00 & 0.00 & 0.00 & 0.00 \\
Shanxi (SHX) & 0.05 & 0.00 & 0.01 & 0.01 & 0.01 & 0.00 & 0.01 & 0.01 & 0.01 \\
Inner-Mongo (IN-MON) & 0.04 & 0.00 & 0.00 & 0.01 & 0.01 & 0.00 & 0.00 & 0.01 & 0.00 \\
Liaoning (LN) & 0.05 & 0.00 & 0.00 & 0.00 & 0.00 & 0.00 & 0.02 & 0.01 & 0.00 \\
Jilin (JL) & 0.25 & 0.00 & 0.06 & 0.08 & 0.04 & 0.00 & 0.00 & 0.06 & 0.01 \\
Heilongjiang (HLJ) & 0.24 & 0.00 & 0.04 & 0.08 & 0.03 & 0.00 & 0.01 & 0.06 & 0.01 \\
Shanghai (SH) & 0.03 & 0.00 & 0.00 & 0.00 & 0.00 & 0.00 & 0.02 & 0.01 & 0.00 \\
Jiangsu (JS) & 0.08 & 0.00 & 0.00 & 0.02 & 0.01 & 0.00 & 0.02 & 0.03 & 0.00 \\
Zhejiang (ZJ) & 0.27 & 0.00 & 0.05 & 0.02 & 0.05 & 0.01 & 0.05 & 0.09 & 0.01 \\
Anhui (AH) & 0.23 & 0.00 & 0.03 & 0.03 & 0.04 & 0.00 & 0.03 & 0.08 & 0.01 \\
\hline
\end{tabular}

\footnotetext{
${ }^{3}$ For simplicity, this paper will only report results assuming VRS. If readers are interested in the results assuming CRS, please contact the corresponding author.
} 


\begin{tabular}{|c|c|c|c|c|c|c|c|c|c|}
\hline Fujian (FJ) & 0.12 & 0.00 & 0.00 & 0.00 & 0.04 & 0.00 & 0.02 & 0.05 & 0.00 \\
\hline Jiangxi (JX) & 0.18 & 0.00 & 0.02 & 0.06 & 0.03 & 0.00 & 0.02 & 0.04 & 0.00 \\
\hline Shandong (SD) & 0.07 & 0.01 & 0.01 & 0.01 & 0.01 & 0.00 & 0.01 & 0.01 & 0.00 \\
\hline Henan (HEN) & 0.12 & 0.00 & 0.02 & 0.03 & 0.01 & 0.01 & 0.01 & 0.04 & 0.00 \\
\hline Hubei (HUB) & 0.10 & 0.00 & 0.01 & 0.02 & 0.02 & 0.00 & 0.01 & 0.03 & 0.00 \\
\hline Hunan (HUN) & 0.16 & 0.00 & 0.01 & 0.03 & 0.02 & 0.00 & 0.02 & 0.06 & 0.01 \\
\hline Guangdong (GD) & 0.04 & 0.00 & 0.00 & 0.01 & 0.00 & 0.00 & 0.01 & 0.02 & 0.00 \\
\hline Guangxi (GX) & 0.22 & 0.00 & 0.04 & 0.04 & 0.04 & 0.00 & 0.02 & 0.07 & 0.01 \\
\hline Hainan (HAN) & 0.07 & 0.00 & 0.01 & 0.02 & 0.03 & 0.00 & 0.00 & 0.01 & 0.00 \\
\hline Chongqing (CQ) & 0.26 & 0.00 & 0.03 & 0.06 & 0.06 & 0.00 & 0.01 & 0.08 & 0.01 \\
\hline Sichuan (SC) & 0.27 & 0.00 & 0.04 & 0.04 & 0.06 & 0.01 & 0.03 & 0.08 & 0.00 \\
\hline Guizhou (GZ) & 0.00 & 0.00 & 0.00 & 0.00 & 0.00 & 0.00 & 0.00 & 0.00 & 0.00 \\
\hline Yunnan (YN) & 0.24 & 0.00 & 0.06 & 0.02 & 0.04 & 0.02 & 0.02 & 0.07 & 0.01 \\
\hline Shaanxi (SH'X) & 0.09 & 0.00 & 0.01 & 0.02 & 0.02 & 0.00 & 0.01 & 0.02 & 0.00 \\
\hline Gansu (GS) & 0.04 & 0.00 & 0.01 & 0.01 & 0.01 & 0.00 & 0.00 & 0.01 & 0.01 \\
\hline Qinghai (QH) & 0.01 & 0.00 & 0.01 & 0.00 & 0.01 & 0.00 & 0.00 & 0.00 & 0.00 \\
\hline Ningxia (NX) & 0.01 & 0.00 & 0.00 & 0.00 & 0.00 & 0.00 & 0.00 & 0.00 & 0.00 \\
\hline Xinjiang (XJ) & 0.20 & 0.00 & 0.05 & 0.03 & 0.03 & 0.01 & 0.01 & 0.07 & 0.01 \\
\hline Average & 0.12 & 0.00 & 0.02 & 0.02 & 0.02 & 0.00 & 0.01 & 0.04 & 0.00 \\
\hline
\end{tabular}

As Table 3 shows, the average scores of GIE for 30 province-level regions in 468 China's transport sector during 2006-2015 is 0.12. Generally speaking, inefficiency 469 scores associated with energy use $(E)$, value added $(Y)$ and $\mathrm{CO}_{2}$ emissions $(C)$ induced 470 by the BAM model is zero. Note that the zero inefficiency for value added $(Y)$ is 471 coherent with most previous researches (e.g., Miao et al., 2019a). However, the nil 472 inefficiency for energy-environment variables (i.e., $E$ and $C$ ) vary greatly from that in 473 Miao et al., (2019a), where inefficiency scores relative to energy-environment 474 variables account for $82 \%$ of the overall inefficiency. As we set managerial 475 disposability for $E$, the nil inefficiency scores indicate expanding clean energy use in 
transport network should be promoted. Turning to $Y$, the additive approach indicates there is limited potential for gaining the value added in transport sector given the existing levels of inputs. Hence, input-oriented structural adjustments are prioritized over input-oriented extensive growth. Looking at $C$, the zero inefficiency score corresponds to the strong assumption for energy use, suggesting that complete clean energy use will results in optimal $\mathrm{CO}_{2}$ emissions. Looking at transport turnover (T1), the GIE is low but no long equals to zero, which can be attributed to the redundancy for $P, K$ and $L$ (all 0.02). Noteworthy, the GIE scores relative to traffic casualties is highest (0.04), accounting for $33.33 \%$ of the overall inefficiency scores, and this corresponds to the results reported in Chen et al., (2019). This indicates traffic casualties have been the roadblock for achieving high efficiency and large potentials exist for improvements in this regard.

Region-wise, substantial variances can be observed for 30 province-level regions and certain patterns can be concluded. For example, HB and GZ have been in the frontier for their nil inefficiency scores. Look at HB, its value added is comparatively more in transport sector whereas it can better coordinate the relationship among energy use, value added and traffic casualties. Hence, its technical efficiency in transport sector is at the forefront of the whole country. Turning to GZ, though its total economic output in transport sector is not high, the level of energy use, civil vehicle possessions, traffic casualties and pollutant emissions can be coordinated with economic development. Due to the relatively high possession intensity of civil vehicle possession per unit area, the level of inefficiency scores in BJ, TJ and SH are generally low $(0.03,0.07$ and 0.03 resp.) whereas they still bear certain pressure of regulations in transport sector. Spatially, the sum of the static inefficiencies of transport sector in central China (e.g., AH, JX, HEN and HUN; 0.23, 0.18, 0.12 and 0.16 resp.) and part of Western China (i.e., CQ, SC, YN and XJ; 0.26, 0.27, 0.24 and 0.20 resp.) exceed that of other parts in the country. For local officials, the situation of atmospheric environment harnessing is grim. 


\subsection{Decomposition from double dimensions for productivity change}

507

508

509

510

511

512

513

51

515

516

517

518

\subsubsection{Variable-specific dimension decomposition}

In this study, we perform the decomposition from two dimensions on the basis of the Luenberger productivity indicator. Note that the panel data representing all the time periods are used to construct the global frontier and panel data from each particular time period are employed to build the current frontier (i.e., we handle data respectively). Combined with equation (11) - (18), the average annual change of TFP of transport sector in China's provincial-level region during 2006-2015 can be

514 calculated. Moreover, according to the additive structure principle of extended 515 Luenberger productivity indicator, ATTFP growth is decomposed into the contribution 516 of each variable. The results are shown in table 4.

517 Table 4. Average Annual Transport Total Factor Productivity change in 30 China's 18 province-level regions, $\%$

\begin{tabular}{lccccccccc}
\hline \multicolumn{1}{c}{ Province } & LTFP & $E$ & $P$ & $K$ & $L$ & $Y$ & $T 1$ & $T 2$ & $C$ \\
\hline BJ & 0.00 & 0.00 & 0.00 & 0.00 & 0.00 & 0.00 & 0.00 & 0.00 & 0.00 \\
TJ & 2.71 & 0.14 & 0.18 & 0.57 & 0.67 & 0.00 & 0.08 & 1.12 & 0.10 \\
HB & 0.00 & 0.00 & 0.00 & 0.00 & 0.00 & 0.00 & 0.00 & 0.00 & 0.00 \\
SHX & 4.43 & 0.16 & 0.53 & 0.94 & 0.74 & 0.26 & 0.08 & 1.03 & 0.84 \\
IN-MON & 0.89 & 0.21 & 0.01 & 0.31 & 0.78 & 0.00 & -0.10 & -0.49 & 0.39 \\
LN & 2.67 & 0.59 & 0.20 & 0.00 & 0.38 & 0.00 & 1.39 & 0.33 & 0.37 \\
JL & 1.68 & 0.10 & 0.29 & 0.17 & 0.35 & 0.00 & 0.02 & 0.16 & 0.68 \\
HLJ & 2.35 & 0.13 & 0.30 & 0.06 & 0.76 & 0.00 & 0.13 & 0.27 & 0.83 \\
SH & 0.00 & 0.00 & 0.00 & 0.00 & 0.00 & 0.00 & 0.00 & 0.00 & 0.00 \\
JS & 1.61 & 0.59 & 0.24 & -0.04 & 0.08 & 1.11 & 0.00 & -0.27 & 0.49 \\
ZJ & 1.59 & 0.38 & 0.43 & 0.28 & 0.27 & 0.34 & 0.00 & -0.28 & 0.56 \\
\hline
\end{tabular}




\begin{tabular}{|c|c|c|c|c|c|c|c|c|c|}
\hline $\mathrm{AH}$ & 2.23 & 0.24 & 0.73 & -0.15 & 0.41 & 0.09 & 0.77 & -0.27 & 0.66 \\
\hline FJ & 1.71 & 0.38 & 0.00 & 0.00 & 0.71 & 0.00 & 0.19 & 0.73 & 0.08 \\
\hline JX & 3.67 & 0.14 & 0.42 & 0.96 & 0.61 & 0.00 & 0.00 & 0.86 & 0.82 \\
\hline SD & 4.65 & 0.60 & 0.51 & 0.36 & 0.37 & 1.11 & 1.39 & 0.47 & 0.43 \\
\hline HEN & 1.14 & 0.49 & 0.57 & 0.05 & 0.12 & 0.28 & 0.74 & -0.80 & 0.19 \\
\hline HUB & 3.30 & 0.52 & 0.44 & 0.00 & 0.71 & 0.00 & 0.93 & 1.00 & 0.22 \\
\hline HUN & 3.72 & 0.33 & 0.37 & 0.14 & 0.82 & 0.00 & 1.39 & 0.45 & 0.56 \\
\hline GD & 1.77 & 0.62 & 0.32 & 0.27 & 0.62 & -0.16 & 0.00 & 0.02 & 0.69 \\
\hline GX & 2.24 & 0.15 & 0.40 & 0.44 & 0.68 & 0.00 & -0.12 & -0.04 & 0.88 \\
\hline HAN & 0.43 & 0.04 & 0.03 & 0.00 & -0.33 & 0.00 & 0.00 & 0.00 & 0.73 \\
\hline CQ & 1.66 & 0.15 & 0.28 & 0.01 & 0.46 & 0.10 & 0.03 & -0.08 & 0.87 \\
\hline $\mathrm{SC}$ & 1.74 & 0.23 & 0.28 & 0.64 & 0.79 & 0.00 & -0.57 & 0.12 & 0.48 \\
\hline GZ & -0.81 & 0.00 & -0.18 & -0.20 & 0.00 & -0.01 & -0.01 & -0.41 & 0.00 \\
\hline YN & 4.52 & 0.05 & 0.63 & 0.95 & 1.23 & 0.12 & -0.10 & 0.47 & 1.23 \\
\hline SH'X & 3.10 & 0.13 & 0.44 & 0.51 & 0.65 & 0.24 & -0.02 & 0.41 & 0.87 \\
\hline GS & 5.72 & 0.05 & 0.92 & 1.27 & 1.06 & 0.00 & 0.00 & 1.38 & 1.09 \\
\hline $\mathrm{QH}$ & 2.29 & 0.02 & 1.17 & 0.00 & -0.01 & 0.00 & -0.03 & 0.00 & 1.15 \\
\hline NX & 5.14 & 0.04 & 0.69 & 1.39 & 0.78 & 0.01 & 0.01 & 1.39 & 0.87 \\
\hline XJ & 3.42 & 0.10 & 0.47 & 0.99 & 0.62 & -0.03 & 0.03 & 0.28 & 1.06 \\
\hline Average & 2.32 & 0.22 & 0.36 & 0.33 & 0.48 & 0.11 & 0.21 & 0.26 & 0.57 \\
\hline
\end{tabular}

519 As is presented in table 4, the total growth rate of AAT-TFP is $2.32 \%$ across 520 2006-2015. The variable-specific decomposition indicates all variables contribute 521 positively to the overall productivity gains, with the highest share of $C$ and $L(0.57 \%$ 522 and $0.48 \%$ ). This indicates regulation policies on $C$ and labor force have achieved 523 high-quality progress, whereas $Y$ is comparatively lagged $(0.11 \%)$. This corresponds 524 to the inefficiency scores presented in Table 4. Specifically, higher inefficiency scores 525 indicate more potential for improvements (e.g., $P, K, L$ and $T 2$ ). Conversely, lower 526 inefficiency scores suggest limited potentials for improvements (e.g., $Y$ and $E$ ). 
528 Regionally, substantial variances can be observed. Looking at GZ, the joint results of 529 nil inefficiency (0.00) and negative productivity change (-0.81) imply the existing 530 inputs can not achieve connotative development, and then input-oriented structure 531 adjustments in transport sector are required. Turning to BJ, TJ and China's 532 southeastern coastal areas, lower inefficiency scores are observed, e.g., $0.00 \%$ for BJ, 5330.00 for $\mathrm{SH}, 1.61 \%$ for JS and $1.59 \%$ for $\mathrm{ZJ}$. Whereas western province-level regions 534 hold relative larger productivity gains, e.g., 5.72\% for GS, 5.14\% for NX. Spatially, 535 the productivity change in transport sector presented is lower in southeast regions and 536 going increase to northwest regions gradually.

\subsubsection{Time dimension decomposition}

Average annual transport productivity change can then be obtained. For simplicity, the results are shown in Supplementary materials (table A1). Fig. 2 then presents the changing trend of the annual productivity. For measuring the spatial variances, we further divide 30 province-level regions into 3 groups (i.e., Western regions, Central regions and Eastern regions) $)^{4}$.

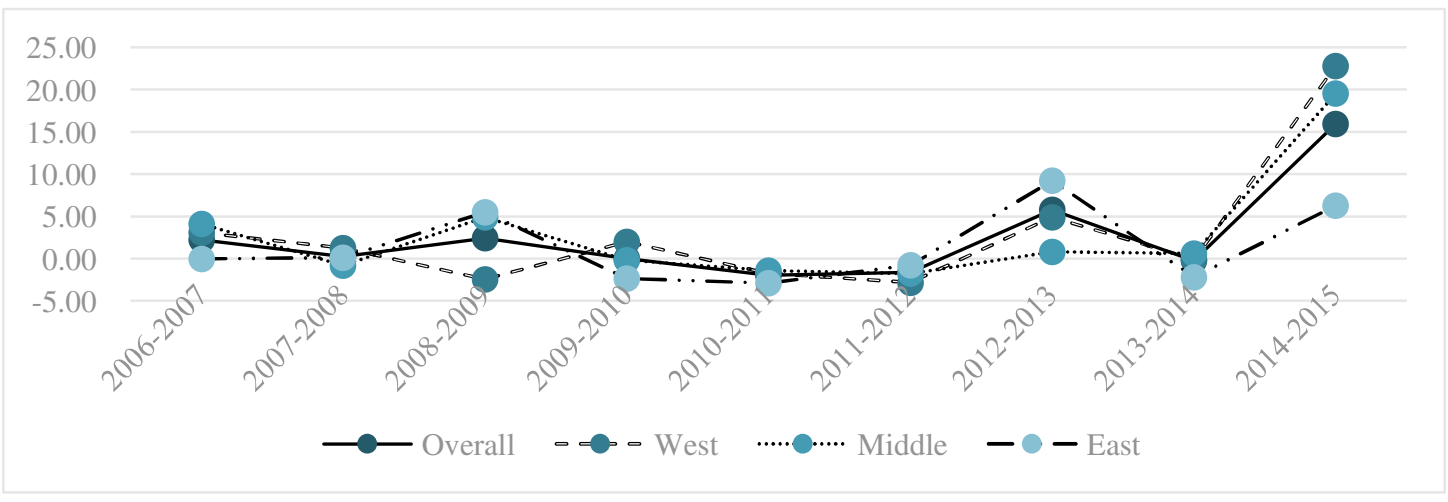

\footnotetext{
${ }^{4}$ The east regions include BJ, TJ, HEB, LN, SH, JS, ZJ, FJ, SD, GD and HAN, the central regions include SHX, JL, HLJ, AH, JX, HEN, HUB, HUN, and the west regions include IN-MON, GX, SC, CQ, GZ, YN, SH'X, GS, QH, NX and XJ.
} 
545 In general, as shown in Fig. 2, the elongated left W-shaped distribution is observed 546 for TFP during 2006-2015 in China's transport sector. Whereas, the variances of 547 ATTFP across 2006-2015 for spatial regions are limited. The productivity change 548 during 11th Five-Year Plan (2006-2010) is generally lower than that during 12th 549 Five-Year Plan (2011-2015). Note that productivity change during 2006-2010 is 550 comparative stable while generally hold a slight decrease whereas that across 551 2011-2015 go through greater volatility while generally hold steep gains. Spatially, 552 during 12th Five-Year Plan, western regions presented better performance in 553 productivity change, and eastern regions hold great variances (with highest TFP 554 during 2012-2013 and lowest TFP during 2014-2015).

\subsection{Source-decomposition of productivity change}

557

558

559

560

561

562

563

564

565

566

567

568

The growth rates of $A A T-T F P$ and its corresponding decomposition results with respect to individual variables of China's transport sector has been obtained in the above part. However, the purposes of find the driving effect of catch-up effect and frontier movement force us to seek for source-decomposition of the productivity changes. According to Eq. (11) - (14), AATTFP in China's 30 provinces can further be broken down into efficiency change (AAT-EC, i.e., catch-up effect) and technological change (AAT-TP, i.e., frontier movement). Moreover, according to Eq. (15) - (18), $A A T-E C$ can then be broken down into pure efficiency change (LPEC) and scale efficiency change ( $L S E C)$. Meanwhile, technological change $(L T P)$ can be further decomposed into pure technological progress $(L P T P)$ and technological progress of scale change (LTPSC). Fig 3 present the decomposition results of LTFP, LEC and LTP in China's transport sector 30 province-level regions ${ }^{5}$.

\footnotetext{
5 The detailed results are available in contacting the corresponding author.
} 


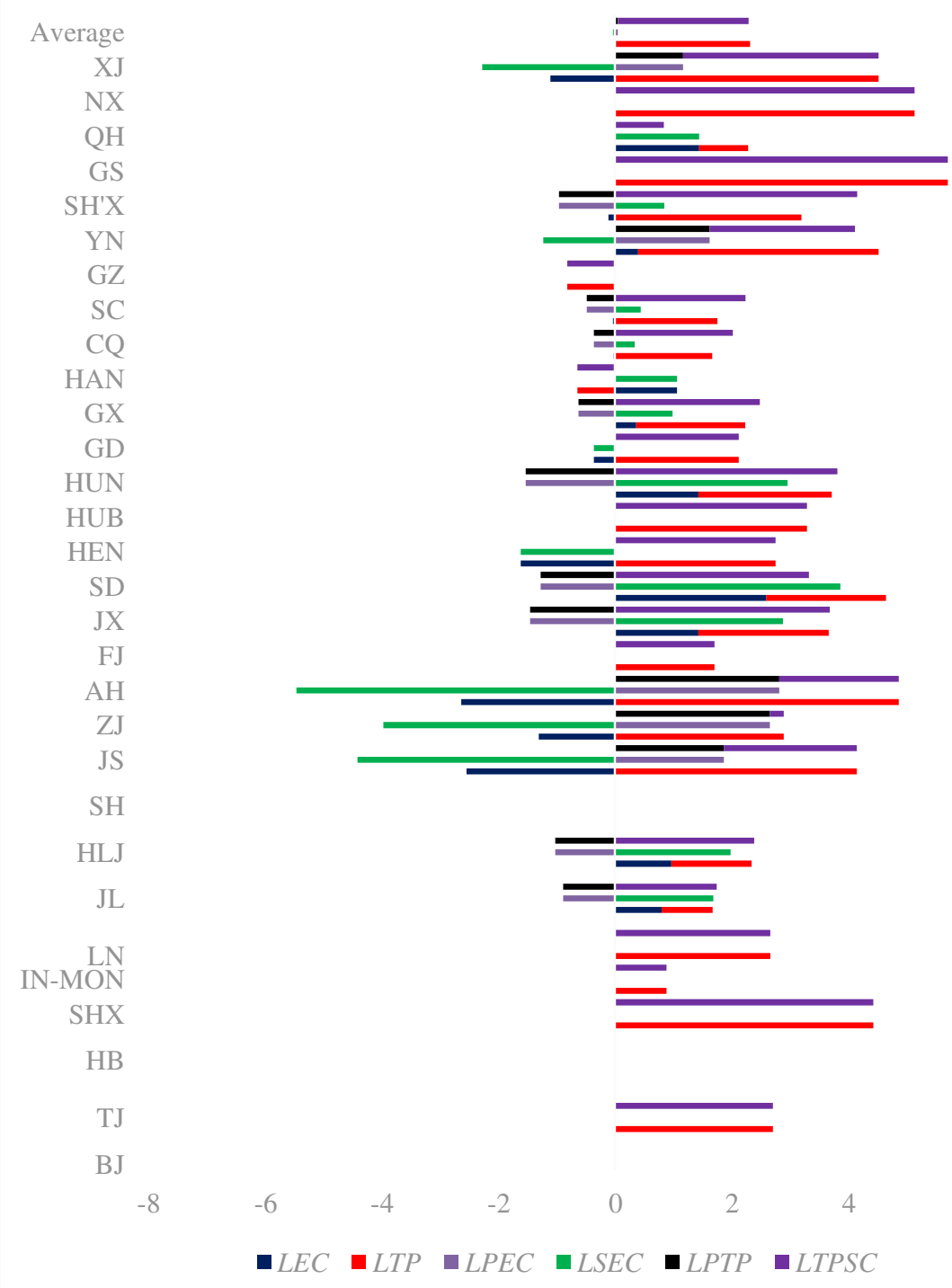

570 Fig. 3. Cumulative decomposition results of LTFP, LEC and LTP of 30 province-level regions across 2006-2015, \%

572 The decomposition results for $A A T-T F P$ reveal that the average productivity change in 573 the transport of the whole state due to catch-up effect is $0.03 \%$ (as shown in Fig. 3), 574 whereas that due to frontier movement is $2.29 \%$. This indicates technological progress 575 contributes to $98.7 \%$ to the overall productivity change, and efficiency change only 576 have faint positive effects to TFP. Such results are basically consistent with that 577 reported in Zha et al., (2019). Region-wise, substantial variances can be observed. 578 Looking at technological progress, only HAN and GZ present negative growth rates $579(-0.64 \%$ and $-0.81 \%$ resp.), which indicates relative lagged technology and 
580

581

582

583

584

585

586

587

588

589

590

591

592

593

594

595

596

597

598

599

600

601

602

603

604

605

606

607

technological process is key in promoting TFP. Noteworthy, the growth rates of efficiency change in HAN is steep (1.07\%), while than in GZ is nil. This suggests that though HAN holds bad performance, the province-level region is pursuing the province-level region that located in the frontier, whereas GZ fails. On the contrary, the technological gains of transport sector in SHX, JS, AH, YN, GS, NX and XJ is superior to the national average level $(4.43 \%, 4.15 \%, 4.87 \%, 4.12 \%, 5.72 \%, 5.14 \%$ and $4.52 \%$ resp.).

Turning to the efficiency change $(0.03 \%)$, the subtle positive effects can be attributed to pure efficiency change ( $L P E C, 0.05 \%)$, whereas scale efficiency change still plays a negative (LSEC, $-0.03 \%$ ) role. Such conclusion accords with that from Yu et al., (2017). Spatially, on one hand, JS, ZJ and AH have steeper pure efficiency change than that of the national level $(1.87 \%, 2.66 \%$ and $2.82 \%$ resp.), whereas their scale efficiency change is much lower $(-4.41 \%,-3.97 \%$ and $-5.46 \%$ resp.). As a result, efficiency change in these regions is inferior to that of the average level in the nation. On the other hand, JX, SD and HUN are associated with lower pure efficiency change $(-1.45 \%,-1.27 \%$ and $-1.53 \%$ resp.), whereas their higher scale efficiency change distinguish them $(2.88 \%, 3.87 \%$ and $2.96 \%$ resp.) in efficiency change $(1.43 \%, 2.59$ and $1.43 \%$ resp.).

Both the pure technological progress and technological progress of scale change contribute to the technological progress (2.29\%), whereas subtly positive (LPTP, $0.05 \%)$ and steep positive effects (LTPSC, 2.24\%) are observed respectively. Note that, among province-level regions relative to higher technological progress, two patterns of LPTP and LTPSC can be obtained. The first pattern is that, technological progress completely relies on LTPSC (e.g., SHX, GS and NX), while the second pattern is that technological progress depends both on LPTP and LTPSC (e.g., JS, AH and $\mathrm{YN}$ ). Noteworthy, BJ and $\mathrm{SH}$, as the mega-cities, own nil growth rates for all 
Luenberger indicators. Hence, the joint results of nil inefficiency scores and constant nil productivity change indicate that these regions are in the frontier and potential for improvements are limited. In the latter stage, transport management policies may promote their productivity gains.

\subsection{Underlying trends of technological change}

On the basis of Eq. (19)-(22), we can further perform decomposition on technological change along time-dimension $(P T)$ and quantity dimension $(P Q)$. This permits depicting the paths of technological change. Fig. 4 describes the performance matrix of average annual growth rates of $P T$ and $P Q$ in transport sector of 30 province-level regions across 2006-2015. Specifically, in order to investigate the relationship between $P T$ and $P Q$, we place results of these two indicators along horizontal axis and vertical axis respectively. The average value of $P T(-4.18 \%)$ and $P Q(21.52 \%)$ in the whole country is regarded as the base point.

We compare the relationships between $P Q$ and $P T$ and have a interesting finding that $P Q$ is strictly greater than or equal to $P T$ (i.e., $P Q \geq P T$ ). Note that three situations can be obtained theoretically.

(1) When $P T=P Q$, i.e., $T G_{c}(1)=T G_{c}^{\max }$, the initial period has the worst performance and technological progress can be regarded as robust. Sadly, such case is absent in the paper.

(2) When $0<P T<P Q$, i.e., $T G_{c}(1)<T G_{c}(t)<T G_{c}^{\max }$, comparatively technological regression is obtained across certain periods, whereas technological growth can be obtained compared with that in the initial period. IN-MON, JL, GZ and SH'X are clustered in the situation.

(3) $P T<0$, i.e., $T G_{c}(t)<T G_{c}(1)<T G_{c}^{\max }$, comparatively technological regression can 
634 be observed in the whole sample, whereas technological progress may happen in 635 some certain periods. The remaining 24 province-level regions are clustered in this 636 situation (BJ, TJ, HEB, LN, SH, JS, ZJ, FJ, SD, GD and HAN, SHX, HLJ, AH, JX, HEN, 637 HUB, HUN, GX, SC, CQ, YN, GS, QH, NX and XJ). Hence, real technological progress 638 is limited in transport sector of these regions and promote $P T$ is required.

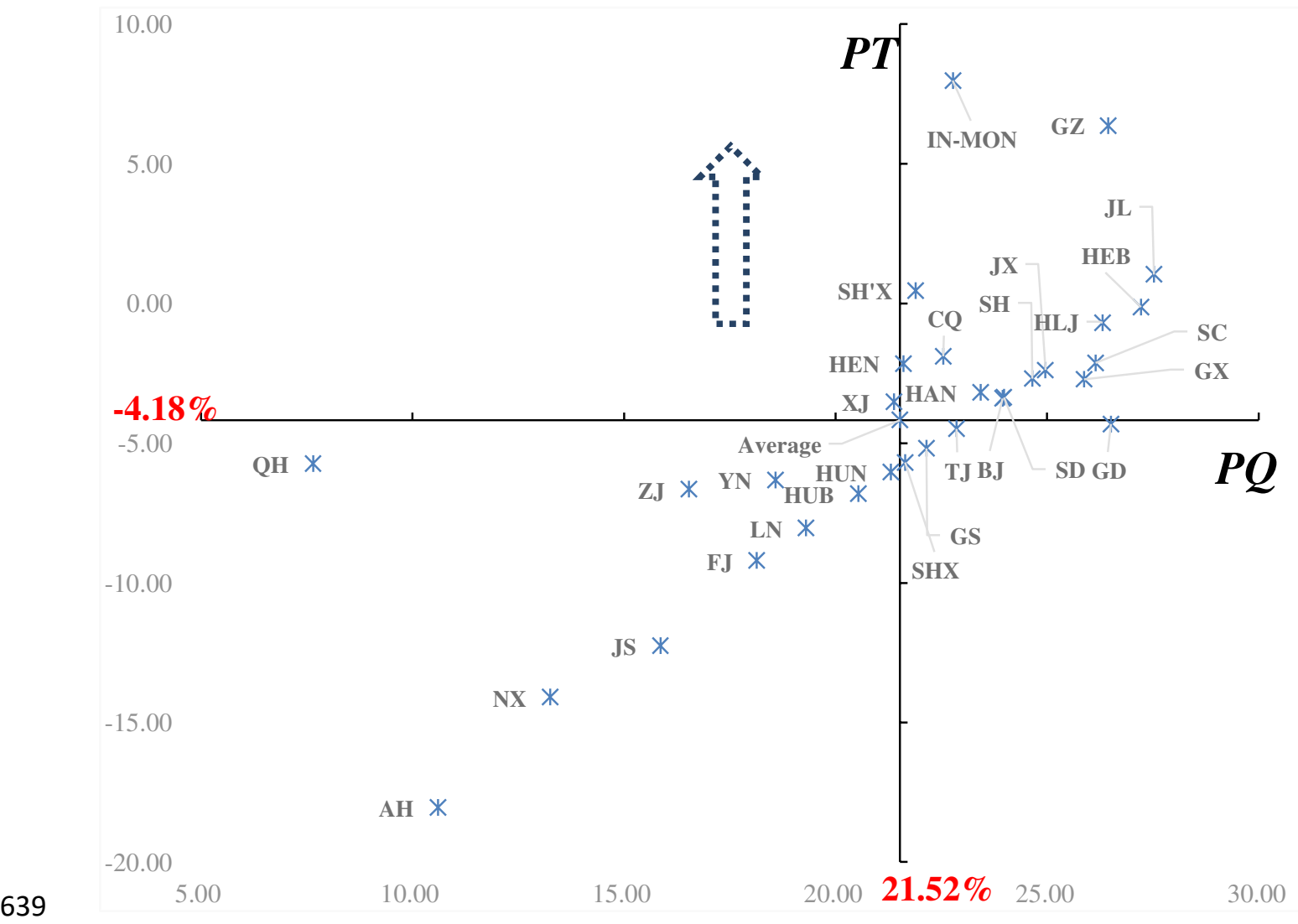

640 641

642

643

\section{Conclusion and discussion}

This paper, introduced the Bounded-adjusted Measure assuming managerial disposability for energy use and natural disposability for conventional inputs. Based on the additive structure, the variable-specific decomposition is performed. This permits attributing the overall inefficiency score to individual variable. In addition, 
650

651

652

653

654

655

656

657

658

659

660

661

662

663

664

665

666

667

668

669

670

671

672

673

674

the calculation of $A A T-T F P$ and source-decomposition for AAT-TFP were investigated. Furthermore, we identify the channels that technological progress affect economic growth.

The study reveals that the average inefficiency score for China's 30 provinces in transport sector is 0.12 , which can be attributed to Civil vehicle, Capital stock, Labor force and Traffic casualties (with the highest share of inefficiency scores). Hence, the government should focus on these variables and improve their efficiency. Noteworthy, the inefficiency score of energy use under managerial disposability is zero, indicating no redundancy regarding clean energy use. Region-wise, south-eastern regions and part of western provinces hold relatively lower inefficiency scores. From time-specific perspective, the elongated left W-shaped distribution is observed for AAT-TFP during 2006-2015 in China's transport sector.

As regards the the decomposition indicator, technological progress (AATP, 2.29\%) promotes greatly to the productivity gains (AAT-TFP, 2.32\%), whereas efficiency change is lagged $(A A E C, 0.03 \%)$. Hence, the tech-transfer of transport production technology in China's 30 provinces needs to be further highlighted, and the spillover effects of management experience in transport ought not to be forgotten. Furthermore, technological progress of scale change (LTPSC, 2.24\%) contributes more to AATP, rather than pure technological change (LPTP, 0.05\%). Simultaneously, pure efficiency change $(L P E C, 0.05 \%)$ pulls the $A A E C$, whereas scale efficiency ( $L S E C,-0.03 \%$ ) plays a negative role. This implies the the technological progress is contributed mainly by the input-output scale change, and technovation in transport sector in the latter stage still needs to be encouraged.

Moreover, we perform the time-dimension $(P T)$ and quantity-dimension $(P Q)$ decomposition for technological progress and divide all 30 province-level regions into 
675 four parts in terms of the the relationship of $P T$ and $P Q$. Results reveal that the 676 average value of $P Q$ and $P T$ is $21.52 \%$ and $-4.18 \%$ respectively. The channels of how 677 technological progress affects economic development in transport sector of each 678 province can be captured in Fig. 4.

679

680

681

682

683

684

685

686

687

688

689

690

691

692

693

694

695

696

697

698

699

700

701

702

703

\section{Authors Contributions}

XC: Conceptualization, Methodology, Writing - original draft, Writing - review \& editing, Formal analysis, Investigation, Supervision, Validation. JZ: Formal analysis, Investigation. FW: Conceptualization, Methodology, Supervision, Validation.

\section{Funding}

We acknowledge the financial support from National Social Science Foundation of China (19BGL152).

\section{Competing Interests}

The authors declare that they have no competing interests.

\section{Availability of data and materials}

The datasets used and/or analysed during the current study are available from the corresponding author on reasonable request.

\section{References}

Beier, R.. The world-class city comes by tramway: Reframing Casablanca's urban peripheries through public transport. Urban Studies, 2019, 57(9), 1827-1844.

Boussemart, J., Ferrier, G., Leleu, H., Shen, Z.. An expanded decomposition of the Luenberger productivity indicator with an application to the Chinese healthcare sector, Omega, 2020, 91, 102010.

Bohr, J.. 2020, "Reporting on climate change: A computational analysis of U.S. newspapers and sources of bias, 1997 - 2017”, Global Environmental Change, 2020, $61,102038$.

CESY, 2007-2015.. China Energy Statistical Yearbook. China Statistical Publishing House, Beijing. 
Chang, V., Tovar, B.. Metafrontier analysis on productivity for West Coast of South Pacific terminals, Transportation Research Part A: Policy and Practice, 2017, 103, 118-134.

Chang, Y.T., Zhang, N., Danao, D., Zhang, N., 2013. Environmental efficiency analysis of transportation system in China: a non-radial DEA approach. Energy Policy 58, 277-283.

Charnes, A., Cooper, W. and Rhodes, E. Measuring the efficiency of decision-making units. European Journal of Operational Research, 1978, 2: 429-444.

Chen X, Wu G, Li D, 2019. Efficiency measure on the truck restriction policy in China: A non-radial data envelopment model. Transportation Research Part A: policy and practice 129, 140-154.

Chen X., Miao, Z., Wang, K., Sun, C. 2020. Assessing eco-performance of transport sector: Approach framework, static efficiency and dynamic evolution. Transportation Research Part D: Transport and Environment. 2020, 85, 102414.

Cohen, T., Jones, P.. Technological advances relevant to transport - understanding what drives them, Transportation Research Part A: Policy and Practice, 2020, 135, 80-95.

Cooper, J., Ryley, T., Smyth, A.. 2001, Energy Trade-offs and Market Responses in Transport and Residential Land-use Patterns: Promoting Sustainable Development Policy. Urban Studies, 38(9), 1573-1588.

Cooper W W, Pastor J T, Borras F, Aparicio J, Pastor D, 2011. BAM: A bounded adjusted measure of efficiency for use with bounded additive models. Journal of Productivity Analysis 35, 85-94.

Cooper W., Park, K., Paster, J.. RAM: A Range Adjusted Measure of Ineffificiency for Use with Additive Models, and Relations to Other Models and Measures in DEA, Journal of Productivity Analysis, 1999, 11, 5-42.

Cooper, W., Seiford, L., Tone, K.. Data Envelopment Analysis (Second Edition) Boston: Kluwer Academic Publishers, 2007.

Cui, Q., Li, Y.. The evaluation of transportation energy efficiency: An application of three-stage virtual frontier DEA, Transportation Research Part D: Transport and Environment, 2014, 29, 1-11.

Cullinane, K., Ji, P., Wang, T.. The relationship between privatization and DEA estimates of efficiency in the container port industry, Journal of Economics and Business, 2005, 57(5), 433-462.

Daraio, C., Diana, M., Costa, F., Leporelli, C., Matteucci, G., Nastasi, A.. Efficiency 
and effectiveness in the urban public transport sector: A critical review with directions for future research, European Journal of Operational Research, 2016, 248(1), 1-20.

Fan, F., Lei, Y., 2016. Decomposition analysis of energy-related carbon emissions from the transportation sector in Beijing. Transport. Res. D: Transp. Environ. 42, $135-145$.

Färe, R., Grosskopf, S., 2004. Modeling undesirable factors in efficiency evaluation: comment. Eur. J. Oper. Res. 157 (1), 242-245.

Feng, C., Wang, M., Analysis of energy efficiency in China's transportation sector, Renewable and Sustainable Energy Reviews, 2018, 94, 565-575.

Fleisher, B., Li, H., Zhao, M.. Human capital, economic growth, and regional inequality in China, Journal of Development Economics, 2010, 99(2), 215-231.

Gehringer, Uneven effects of financial liberalization on productivity growth in the EU: Evidence from a dynamic panel investigation, International Journal of Production Economics, 2015, 159, 334-346.

Hao, H., Geng, Y., Li, W., Guo, B.. Energy consumption and GHG emissions from China's freight transport sector: Scenarios through 2050, Energy Policy, 2015, 85, 94-101

Huang, F., Zhou, D., Wang, Q., Hang, Y.. Decomposition and attribution analysis of the transport sector's carbon dioxide intensity change in China, Transportation Research Part A: Policy and Practice, 119, 343-358

Ilmakunnas, P., Miyakoshi, T.. What are the drivers of TFP in the Aging Economy? Aging labor and ICT capital, Journal of Comparative Economics, 2013(41), 201-211.

IEA, 2016, https://www.iea.org/

International Energy Agency, 2014, $\mathrm{CO}_{2}$ Emissions from Fuel Combustion:

IPCC, 2006. IPCC guidelines for national greenhouse gas inventories (accessed April 1, 2020). http://www.ipcc-nggip.iges.or.jp/public/2006gl/vol2.html.

Jin, J., Wang, X., Gao, Y.. Gender differences in farmers' responses to climate change adaptation in Yongqiao District, China, Science of The Total Environment, 538(15), 2015, 942-948

Kannan, R., Hirschberg, S.. Interplay between electricity and transport sectors Integrating the Swiss car fleet and electricity system, Transportation Research Part A: Policy and Practice, 2016, 94, 514-531. 
Krautzberger, L., Wetzel, H., 2012. Transport and $\mathrm{CO}_{2}$ : productivity growth and carbon dioxide emissions in the European commercial transport industry. Environ. Resour. Econ. 53 (3), 435-454.

Legacy, C., Transforming transport planning in the postpolitical era. Urban Studies. 2015, 53(14), 3108-3124.

Li, T., Yang, W., Zhang, H., Cao, X., 2016. Evaluating the impact of transport investment on the efficiency of regional integrated transport systems in China. Transp. Policy 45, 66-76.

Li, Y., Du, Q., Lu, X., Wu, J., Han, X.. Relationship between the development and CO2 emissions of transport sector in China, Transportation Research Part D: Transport and Environment, 74, 2019, 1-14

Liu, H., Wu, J., Chu, J.. Environmental efficiency and technological progress of transportation industry-based on large scale data, Technological Forecasting and Social Change, 144, 2019, 475-482

Liu, S., Triantis, K., Sarangi, S.. A framework for evaluating the dynamic impacts of a congestion pricing policy for a transportation socioeconomic system, Transportation Research Part A: Policy and Practice, 44(8), 2010, 596-608

Mahdiloo, Ngwenyama, O., Scheepers, R., Tamaddoni, A.. Managing emissions allowances of electricity producers to maximize $\mathrm{CO}_{2}$ abatement: DEA models for analyzing emissions and allocating emissions allowances, International Journal of Production Economics, 2018, 205, 244-255.

Mahmoudi, R., Shetab-Boushehri, S., Hejazi, S., Emrouznejad, A., Rajabi, P.. A hybrid egalitarian bargaining game-DEA and sustainable network design approach for evaluating, selecting and scheduling urban road construction projects, Transportation Research Part E: Logistics and Transportation Review, 2019, 130, 161-183.

Miao, Z., Chen, X., Baležentis, T., Sun, C.. 2019a, Atmospheric environmental productivity across the provinces of China: Joint decomposition of range adjusted measure and Luenberger productivity indicator,. Energy Policy, 132, 665-677.

Miao, Z., Baležentis, T., Shao, S., Chang, D.. Energy use, industrial soot and vehicle exhaust pollution-China's regional air pollution recognition, performance decomposition and governance. Energy Economics, 2019b, 83, 501-514.

Ministry of Transport of the People's Republic of China, 2019. accessed in March, 2019. http://www.mot.gov.cn/

Monios, J., Geographies of governance in the freight transport sector: The British case, Transportation Research Part A: Policy and Practice, 2019, 121, 295-308. 
National Bureau of Statistics, 2019. accessed in March, 2019. http://www.stats.gov.cn/

NBSC, 2006-2015, National Data. Accessed January 252020, . http://data.stats.gov.cn/english/.

Oh, D., Heshmati, A.. A Sequential Malmquist-Luenberger Productivity Index: Environmentally Sensitive Productivity Growth Considering Progressive Nature of Technology, Energy Economics, 2010, 32(6), 1345-1355.

Oum, T., Pathomsiri, S., Yoshida, Y.. Limitations of DEA-based approach and alternative methods in the measurement and comparison of social efficiency across firms in different transport modes: An empirical study in Japan, Transportation Research Part E: Logistics and Transportation Review, 2013, 57, 16-26.

Pettersson, F., Westerdahl, S., Hansson, J.. Learning through collaboration in the Swedish public transport sector? Co-production through guidelines and living labs, Research in Transportation Economics, 2018, 69, 394-401.

Pilli-Sihvola, K., Aatola, P., Ollikainen, M., Tuomenvirta, H.. Climate change and electricity consumption - Witnessing increasing or decreasing use and costs? Energy Policy, 2010, 38(5), 2409-2419

Saeedi, H., Behdani, B., Wiegmans, B., Zuidwijk, R.. Assessing the technical efficiency of intermodal freight transport chains using a modified network DEA approach,Transportation Research Part E: Logistics and Transportation Review. 2019, 126, 66-86.

Seufert, J., Arjomandi, A., Dakpo, K.. Evaluating airline operational performance: A Luenberger-Hicks-Moorsteen productivity indicator, Transportation Research Part E: Logistics and Transportation Review, 2017, 104, 52-68.

Stefaniec, A., Hosseini, K., Xie, J., Li, Y.. Sustainability assessment of inland transportation in China: A triple bottom line-based network DEA approach, Transportation Research Part D: Transport and Environment, 2020, 80, 102258

Stefaniec, Agnieszka (2020), "Data for: Sustainability assessment of inland transportation in China: A triple bottom line-based network DEA approach”, Mendeley Data, v3http://dx.doi.org/10.17632/6crh35nc96.3

Sueyoshi T, Goto M, 2011. DEA approach for unified efficiency measurement: assessment of Japanese fossil fuel power generation. Energy Economics 33(2), 292-303.

Sueyoshi T, Goto M., 2012. DEA environmental assessment of coal fired power plants: Methodological comparison between radial and non-radial models. Energy Economics 34(6), 1854-1863. 
Tian, Y., Zhu, Q., Lai, K., Lun, Y.. Analysis of greenhouse gas emissions of freight transport sector in China, Journal of Transport Geography, 2014, 40, 43-52.

Venturini, F.. The modern drivers of productivity, Research Policy, 2015, 44(2), 357-369.

Wang, D.. Performance assessment of major global cities by DEA and Malmquist index analysis, Computers, Environment and Urban Systems, 2019, 77, 101365.

Wang, W., Zhang, M., Zhou, M., 2011. Using LMDI method to analyze transport sector $\mathrm{CO}_{2}$ emissions in China. Energy 36 (10), 5909-5915.

World Health Organized, (2018) issued Analysis report on global road traffic safety situation

Yu, Y., Choi, Y., Wei, X., Chen, Z.. Did China's regional transport industry enjoy better carbon productivity under regulations? Journal of Cleaner Production, 2017, $165,777-787$.

Zha, J., Tan, T., Fan, R., Xu, H., Ma, S.. How to reduce energy intensity to achieve sustainable development of China's transport sector? A cross-regional comparison analysis, Socio-Economic Planning Sciences, 2019, 100772.

Zhao, P., Hu, H.. Geographical patterns of traffic congestion in growing megacities: Big data analytics from Beijing, Cities, 2019, 92, 164-174. 
Figures

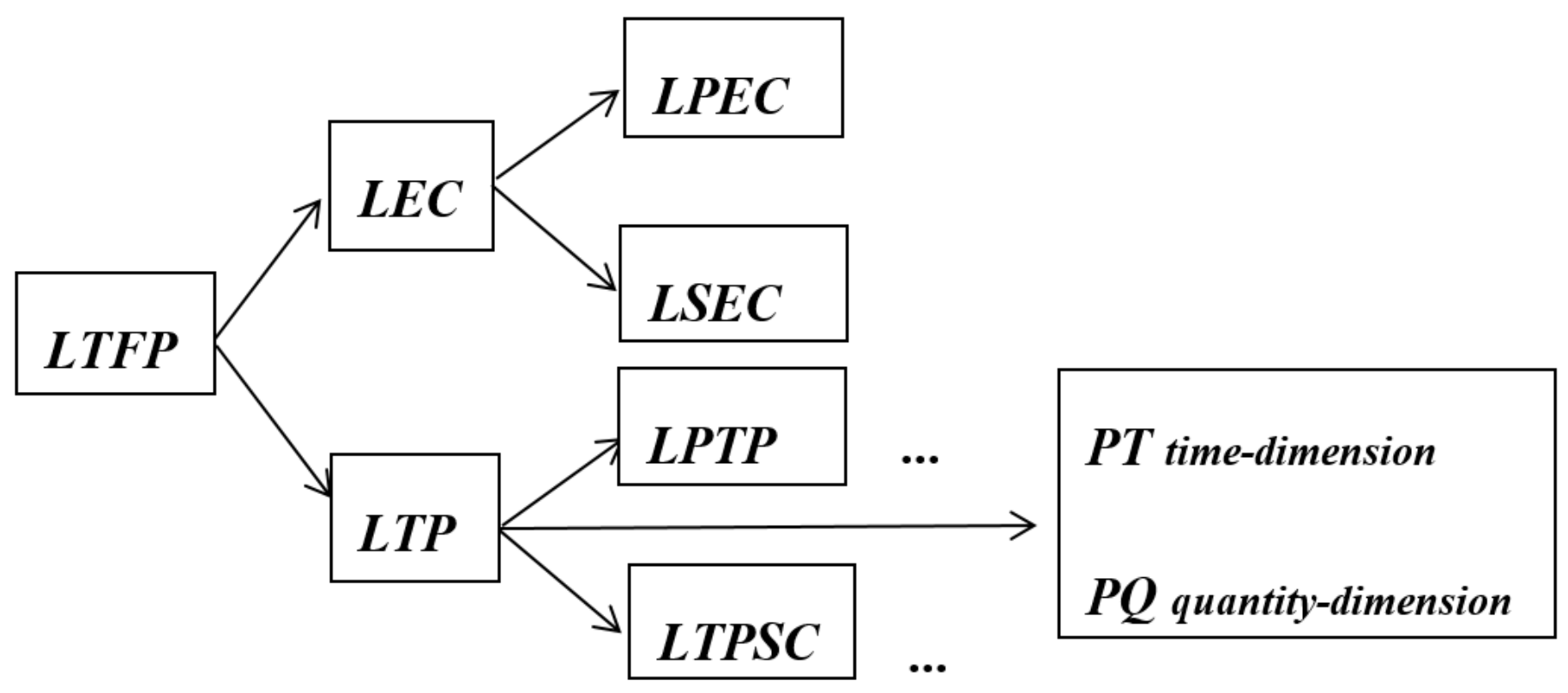

Figure 1

decomposition process for LPI

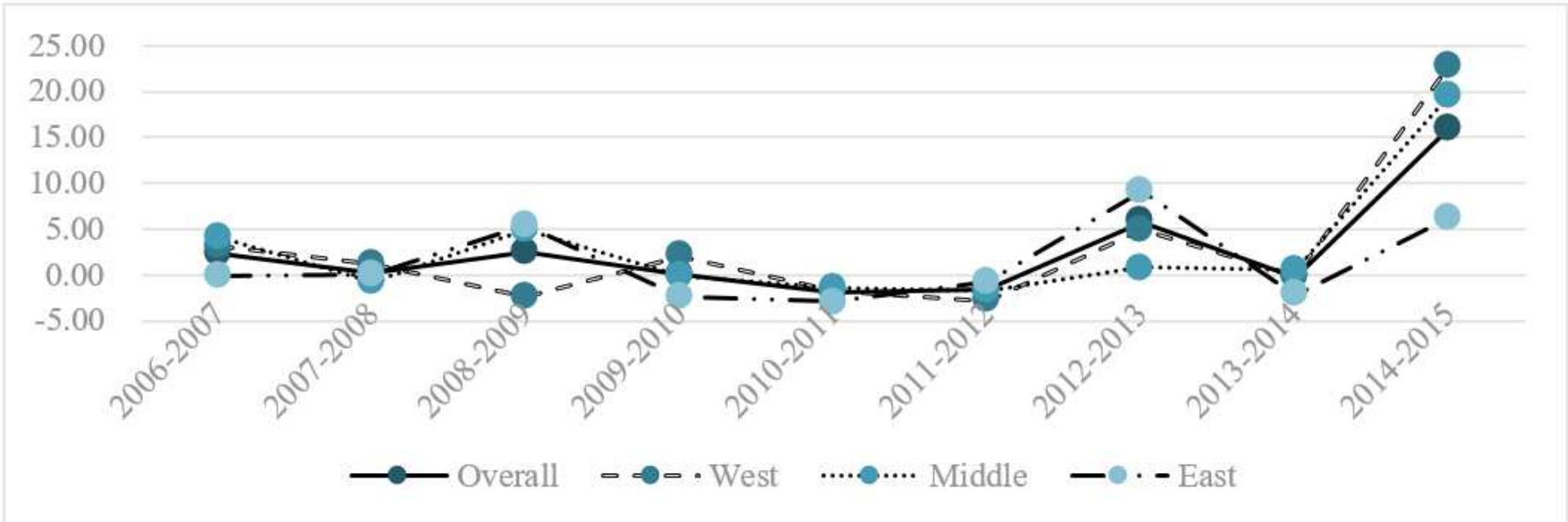

Figure 2

Annual changing trends of TFP in China, \% 


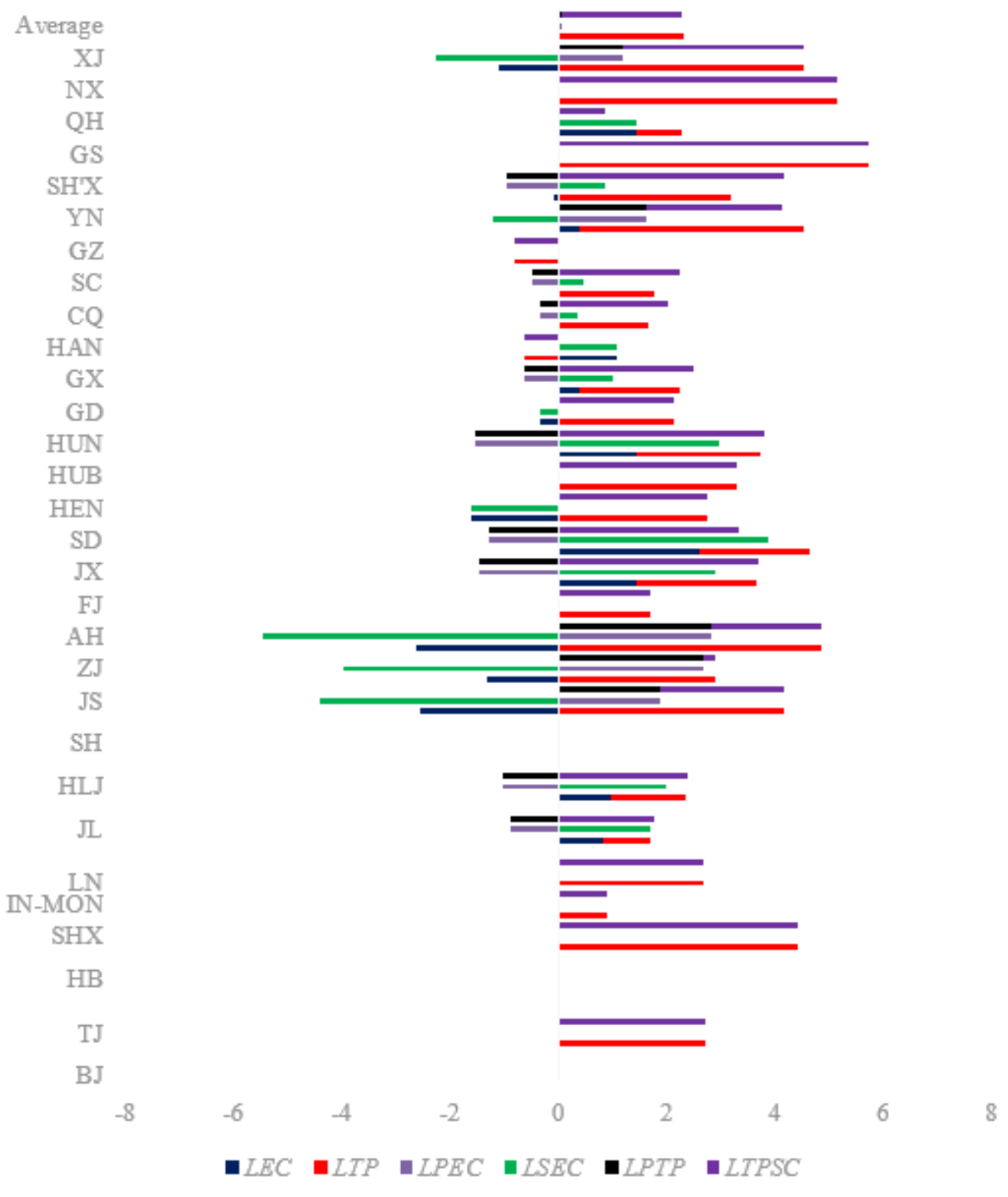

\section{Figure 3}

Cumulative decomposition results of LTFP, LEC and LTP of 30 province-level regions across $2006-2015 \%$ 


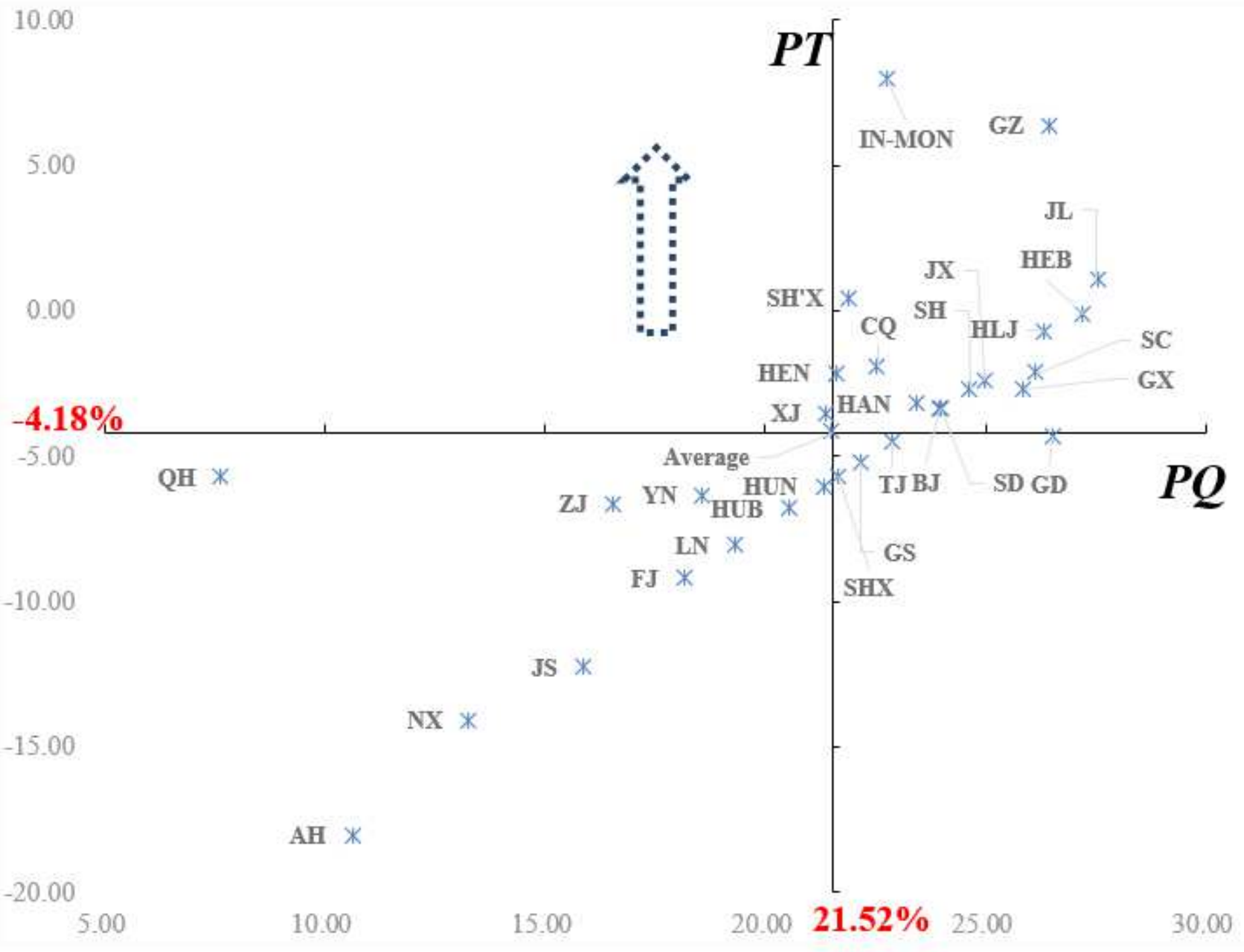

\section{Figure 4}

The performance matrix of average PT and PQ in transport sector of 30 province-level regions across 2006-2015

\section{Supplementary Files}

This is a list of supplementary files associated with this preprint. Click to download.

- Supplementarymaterials.doc 